\title{
Riscos no ambiente de trabalho no setor de panificação: um estudo de caso em duas indústrias de biscoitos
}

\author{
Hazards at workplace in the baking sector: a case study in two \\ cookie industries
}

\author{
Fernando Mota de Vasconcelos \\ Leonardo Rocha Maia ${ }^{2}$ \\ José Adolfo de Almeida Neto ${ }^{2}$ \\ Luciano Brito Rodrigues ${ }^{3}$
}

\begin{abstract}
Resumo: Este trabalho teve como objetivo identificar e analisar os riscos no ambiente de trabalho no setor de panificação em duas indústrias de fabricação de biscoitos de pequeno porte. O levantamento de dados foi feito de forma qualitativa, com identificação e avaliação dos fatores de riscos ambientais ocupacionais (físicos, químicos, biológicos, ergonômicos e de acidentes), observando as normas ISO 14001, OHSAS 18001, AS/NZS 4360, NBR 14009, NBR 14153 e as Normas Regulamentadoras (NR) do Ministério do Trabalho e Emprego. Também foram realizadas medições dos índices de exposição ao ruído e ao calor, conforme a NR 15 e do nível de iluminância nos ambientes, conforme a NR 17. As empresas (denominadas "A" e "B") apresentaram níveis de riscos distintos, classificados como triviais, toleráveis, moderados e substanciais. Dos parâmetros de riscos avaliados, identificou-se que a empresa "B" foi a que apresentou maior exposição ao risco com potencial de causar danos à saúde e à integridade física dos seus trabalhadores, havendo necessidade imediata de intervenção. A partir das indústrias avaliadas, foi possível verificar que, mesmo em meio às exigências legais, as questões relacionadas à saúde e segurança no trabalho são muitas vezes consideradas como fator secundário. Os cuidados relacionados à qualidade, higiene e segurança dos seus produtos são sempre priorizados. Ressalta-se que os gastos efetuados com a prevenção de acidentes e doenças do trabalho devem ser vistos como investimentos, uma vez que poderão contribuir para melhor qualidade de vida dos profissionais, com possibilidades de maximização das atividades por eles desempenhadas.
\end{abstract}

Palavras-chave: Segurança no trabalho; Riscos ambientais; Riscos ocupacionais; Ergonomia; Indústria de alimentos; Setor de panificação.

\begin{abstract}
This work aimed at identifying and analyzing the risks in the workplace of two small-sized cookie manufacturing industries. Data were qualitatively collected, with identification and assessment of occupational risks (physical, chemical, biological, ergonomic and of accidents), observing ISO 14001, OHSAS 18001, AS/NZS 4360, NBR 14009, NBR 14153 standards, and the regulatory standards (NR) of Ministry of Labor and Employment. Noise and heat exposition indexes were measured according to NR 15 protocols and the illuminance level was measured following the NR 17. Both " $A$ " and " $B$ " industries presented different risk levels, classified as trivial, tolerable, moderate and substantial. Industry " $B$ " showed more activities with risk exposition potentially capable of causing damages to the health and physical integrity of its employees, thus demanding immediate need for intervention. It was possible to identify that despite legal exigencies related to health and safety at work, they are still considered as of secondary demand, while attention to the quality, hygiene and safety of foods is prioritized. Expenses with preventing occupational accidents and diseases should be faced as investments, because they may contribute to the quality of life of employees, maximizing the activities they perform.
\end{abstract}

Keywords: Safety at work; Environmental risks; Occupational risks; Ergonomics; Food industry; Bakery sector.

\footnotetext{
${ }^{1}$ Instituto Federal de Educação, Ciência e Tecnologia da Bahia - IFBA, Campus de Vitória da Conquista, Avenida Amazonas, 3150 , Zabelê, CEP 45030-220, Vitória da Conquista, BA, Brasil, e-mail: fernandocelos@hotmail.com

${ }^{2}$ Departamento de Ciências Agrárias e Ambientais, Universidade Estadual de Santa Cruz - UESC, Campus Soane Nazaré de Andrade, Rodovia Jorge Amado, km 16, Bairro Salobrinho, CEP 45662-900. Ilhéus, BA, Brasil, e-mail: eng.leonardomaia@gmail.com; jalmeida@uesc.br

${ }^{3}$ Departamento de Tecnologia Rural e Animal, Universidade Estadual do Sudoeste da Bahia - UESB, Rodovia BR 415, km 03, s/n, CEP 45700-000, Itapetinga, BA, Brasil, e-mail: rodrigueslb@uesb.edu.br
}

Recebido em Maio 17, 2013 - Aceito em Abr. 22, 2015

Suporte financeiro: Universidade Estadual do Sudoeste da Bahia, Edital 011/2010. 


\section{Introdução}

Dados oficiais mostram que o setor de produtos alimentícios e bebidas respondem por $25 \%$ dos acidentes ocorridos na indústria da transformação em 2010, 2011 e 2012, correspondendo ainda entre $6,2 \%$ e $6,5 \%$ do total de acidentes ocorridos nestes anos (Brasil, 2012a).

Por conta desta situação, percebe-se que é cada vez maior, em todos os setores, a preocupação com as questões relacionadas à saúde e à proteção do trabalhador, com a disseminação e a conscientização sobre os riscos e acidentes.

De modo geral, os riscos ocupacionais que podem causar desconforto ambiental são aqueles decorrentes das condições precárias do ambiente de trabalho ou do processo operacional das diversas atividades profissionais. Esses fatores de riscos ambientais estão associados ao ruído, à iluminação, à temperatura, ao esforço físico, à repetitividade, à monotonia, à exigência de postura inadequada, à umidade, à pureza e velocidade do ar, à radiação, ao tipo de vestimenta, aos produtos ou substâncias que podem penetrar no organismo do trabalhador, principalmente pela pele ou ingestão e que, em função de sua natureza, tempo de exposição e intensidade, são capazes de causar danos à saúde e à integridade física do trabalhador. Outros fatores de riscos ambientais são aqueles associados às instalações, máquinas e equipamentos. Estes fatores são agrupados em cinco categorias de riscos denominadas físicos, químicos, biológicos, ergonômicos e de acidentes (SESI, 2005; Rodrigues et al., 2012).

Além dos fatores nocivos ao trabalhador, há também problemas relacionados às condições físicas, organizacionais, administrativas e técnicas existentes nos locais de trabalho, que, por sua vez, também podem ocasionar acidentes de trabalho, além de adoecimentos, como as enfermidades alérgicas respiratórias (asma), que podem acometer os trabalhadores devido a inalação com a farinha (Denipotti \& Robazzi, 2011). Citam-se ainda os problemas devido a utilização de máquinas e equipamentos sem os dispositivos de segurança e na exposição às variações bruscas de temperatura, pela exposição a câmaras frias e fornos. Além destes, tem-se outros fatores, como o levantamento e transporte manual de cargas, contato com produtos químicos utilizados na higiene e limpeza, iluminação inadequada, presença de vetores externos, dentre outros que podem estar presentes em qualquer ambiente de trabalho, e que também podem contribuir para afetar a qualidade de vida e a saúde do trabalhador deste setor produtivo (Rodrigues et al., 2008).

De acordo com a Classificação Brasileira de Ocupações (CBO), na atividade da indústria de panificação, quanto ao trabalhador exposto ao risco de acidente encontra-se a função de padeiro, confeiteiro e afins, codificada com o $\mathrm{n}^{\circ} 8.483$, tendo como descrição sumária o planejamento, a produção e o preparo das massas de pão, macarrão e similares (Brasil, 2010). Além disso, fabricam pães, bolachas, biscoitos e macarrão; elaboram caldas de sorvete e produzem compotas; confeitam doces, preparam recheios e confeccionam salgados; redigem documentos, como as requisições de materiais, registros de saída de materiais e relatórios de produção. Para tanto, necessitam trabalhar em conformidade com as normas e procedimentos técnicos e de qualidade, segurança, higiene, saúde e preservação ambiental (Melo \& Rodrigues, 2005).

Neste sentido, considera-se a necessidade de atuação de forma eficiente e eficaz nos ambientes produtivos das indústrias do setor de panificação para proporcionar àqueles que ali trabalham melhor conforto, bem-estar e medidas de segurança mais adequadas para a prevenção dos acidentes de trabalho e contra os riscos provenientes de cada atividade e ambiente (Rocha et al., 2011). Entretanto, a implantação de medidas de prevenção não pode ser motivada apenas pelo cumprimento das normas e legislações vigentes, o que certamente não terá o mesmo retorno se o objetivo for buscar a segurança e saúde do seu trabalhador.

A análise dos riscos compreende uma ação com capacidade de desenvolver medidas preventivas, além de racionalizar a continuidade de atividades que o trabalhador executa durante seu expediente. Nesse momento, podem-se identificar os riscos de acidentes, a correção de problemas nos processos produtivos e a possibilidade de disseminar informações para execução de forma mais assertiva e segura das etapas de trabalho. Outro benefício na análise e identificação dos riscos no ambiente de trabalho é poder levantar os custos, favorecendo a utilização de técnicas específicas, direcionadas e adequadas à prevenção de acidentes (Sasaki, 2007).

Neste contexto, o presente trabalho teve como objetivo a identificação, análise e classificação dos riscos no ambiente de trabalho do setor de panificação, mais especificamente em duas indústrias de biscoitos em Vitória da Conquista, Bahia, onde foram identificadas as medidas de prevenção e o sistema de gerenciamento de riscos adotado para prevenção de acidentes, indicando ainda ações para as situações de riscos não controladas.

\section{Material e métodos}

A pesquisa teve como universo o setor de panificação, representadas neste estudo por duas indústrias de biscoitos de pequeno porte localizadas na cidade de Vitória da Conquista no Estado da Bahia. A empresa “A” está no mercado desde 2010, possui um efetivo de 28 trabalhadores, sendo 14 mulheres e 14 homens, entre 23 a 30 anos. A empresa "B" está no mercado 
desde 2003 possui 17 trabalhadores, sendo 1 mulher e 16 homens, com idades de 20 a 42 anos. As duas indústrias possuem jornada de trabalho das $7 \mathrm{~h}$ às $17 \mathrm{~h}$, sendo que a indústria “B” apresenta uma jornada complementar (13 h às $22 \mathrm{~h}$ ).

O levantamento de dados foi feito de forma qualitativa, com análise e avaliação dos fatores de riscos ambientais ocupacionais (físicos, químicos, biológicos, ergonômicos e de acidentes), a partir das Normas Regulamentadoras (NR) do Ministério do Trabalho e Emprego, seguido de um método de avaliação adaptado de Rego \& Lima (2006), tendo como base as normas BS 8800 (BSI, 2004), OHSAS 18001 (OHSAS, 2007), AS/NZS 4360 (AS/NZS, 2004), NBR ISO 14001 (ABNT, 2004), NBR 14009 (ABNT, 1997) e NBR 14153 (ABNT, 1998).

O modelo de atuação teve como proposta delimitar os setores das empresas estudadas, identificando os processos e as atividades realizadas em cada uma delas. Para cada processo e atividade, os riscos foram identificados, analisados e avaliados, para, em seguida, definir sua tolerabilidade. Se o risco fosse considerado tolerável, a empresa deveria apenas acompanhar o processo fazendo uso das medidas de controle existentes; no caso de o risco ser considerado como não tolerável, a empresa deveria implantar ações para reduzir o risco a uma condição trivial ou tolerável (Figura 1).

$\mathrm{Na}$ análise dos riscos, considerou-se que o risco pode ter um impacto, uma consequência e uma probabilidade de ocorrência. A metodologia aplicada proporcionou a apresentação e análise do risco de acordo com a frequência de exposição, controle e percepção do risco, efeito (dano), mitigação e repercussão, cujas informações subsidiaram a coleta de informações que, compiladas, proporcionaram a avaliação dos riscos dos processos pesquisados e, em escala mais assertiva, observaram-se os fatores de probabilidade de ocorrência de um risco e de seus principais impactos para, dessa forma, demonstrar à indústria sua exposição e as medidas prioritárias a serem adotadas.

\subsection{Delimitação das áreas, processos e tarefas}

Para realização da pesquisa, foram consideradas as áreas de atuação das indústrias " $\mathrm{A}$ " e " $\mathrm{B}$ ", observando-se, ainda, os processos ou atividades que cada uma realiza. Em cada área de atuação, foram identificados os seus processos em uma Planilha de Levantamento, Identificação e Avaliação de Risco

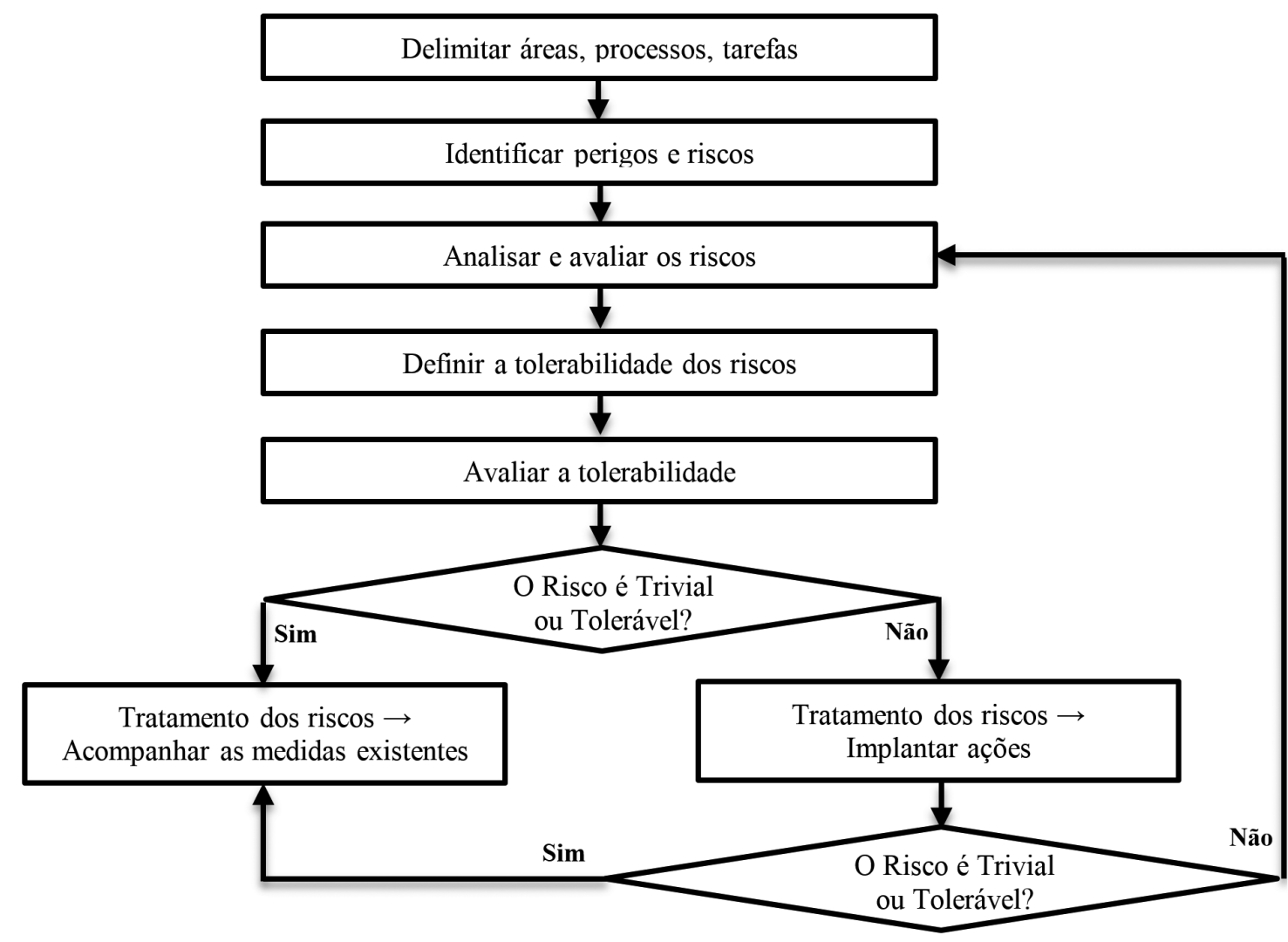

Figura 1. Fluxograma de avaliação qualitativa dos fatores de risco no ambiente de trabalho. Fonte: Adaptação da AS/NZS 4360 (AS/NZS, 2004). 
(Figura 2). O preenchimento da planilha estabeleceu-se conforme apresentado a seguir.

- No topo da planilha: Identificação da área, setor, processo e data de realização da avaliação;

- Identificação de perigo e risco: Definição dos eventos e os resultados que poderiam impactar no alcance do sucesso da indústria. A identificação deveria abranger todos os riscos, estando ou não sob controle da empresa. Os perigos foram analisados de acordo com o regime normal de atividades e situações emergenciais. Para cada atividade, foram identificados os riscos, podendo existir mais de um risco para uma mesma atividade.

\section{- Caracterização da situação operacional da} atividade: Regime Normal de Operação $(\mathrm{N})$ - perigos/riscos que ocorrem quando as tarefas rotineiras ou não rotineiras são executadas ou Regime de Emergência (E) - perigos/riscos que não devem ocorrer durante a execução de uma tarefa, podendo causar acidente ou doença.
- Análise dos riscos: Considerou-se que o risco poderia ter um impacto, uma consequência e uma probabilidade de ocorrência. A análise do risco ocorreu de acordo com a frequência de exposição (Quadro 1), controle e percepção do risco (Quadro 2) para a determinação do fator de risco associado ao perigo (S1) e efeito (dano), mitigação e repercussão (Quadro 3) na determinação do fator de risco associado ao impacto (S2). A significância do risco foi determinada a partir do produto destes dois fatores $(\mathrm{P})$.

\subsection{Avaliação dos riscos}

Os dados levantados foram compilados para a avaliação do risco, em escala mais assertiva, observando-se os fatores de probabilidade de ocorrência de um risco e seus principais impactos. Considerando que se trata de uma escala discreta, há possibilidade do avaliador, em alguma situação, obter resultados com valores na fronteira entre os fatores de risco. Neste caso, tomou-se a decisão de atribuir o risco mais significativo, objetivando assim a precaução em caráter proativo.

\begin{tabular}{|c|c|c|c|c|c|c|c|c|c|c|c|c|c|c|}
\hline \multicolumn{3}{|l|}{ Área: } & \multicolumn{4}{|l|}{ Setor: } & & & \multicolumn{5}{|c|}{ Processo: } & Data: \\
\hline \multicolumn{3}{|c|}{ Identificação } & \multirow{2}{*}{$\begin{array}{c}\text { Característica } \\
\mathrm{N} / \mathrm{E}\end{array}$} & \multicolumn{9}{|c|}{ Análise } & \multirow{2}{*}{$\begin{array}{c}\text { Avaliação } \\
\text { Categoria do } \\
\text { Risco }\end{array}$} & \multirow{2}{*}{$\begin{array}{l}\text { Ger. Riscos } \\
\text { Plano de Ação }\end{array}$} \\
\hline Atividade & Perigo & Dano & & $\mathrm{F}$ & $\mathrm{CA}$ & $\mathrm{PR}$ & $\mathrm{S} 1$ & $\mathrm{E}$ & $\mathrm{M}$ & $\mathrm{R}$ & S2 & $\mathrm{P}$ & & \\
\hline & & & & & & & & & & & & & & \\
\hline & & & & & & & & & & & & & & \\
\hline
\end{tabular}

$\mathrm{N} / \mathrm{E}=$ Normal/Emergencial $; \mathrm{F}=$ Frequência de Exposição $; \mathrm{CA}=$ Controle associado ao perigo; $\mathrm{PR}=$ Percepção de Risco $; \mathrm{S} 1=\mathrm{Soma} 1=\mathrm{F}+\mathrm{CA}+\mathrm{PR} ; \mathrm{E}=$ Efeito e impacto; $\mathrm{M}=$ Mitigação; $\mathrm{R}=$ Repercussão Relativa do Impacto; $\mathrm{S} 2=$ Soma $2=\mathrm{E}+\mathrm{M}+\mathrm{R} ; \mathrm{P}=$ Produto $=(\mathrm{S} 1 \mathrm{xS} 2)$; Ger. Risco $=\mathrm{Gerenciamento}$ dos Riscos.

Figura 2. Planilha de levantamento, identificação e avaliação de risco. Fonte: Rego \& Lima (2006), com adaptações.

Quadro 1. Frequência de exposição para situações normais e de emergência.

\begin{tabular}{|c|c|c|c|}
\hline & CATEGORIA & DESCRIÇÃO & PONTOS \\
\hline \multirow{4}{*}{$\begin{array}{l}\text { Regime de } \\
\text { operação } \\
\text { Normal }\end{array}$} & Altamente Baixa & Menos de 1 (uma) vez por ano & 1 \\
\hline & Baixa & Mais de 1 (uma) vez por ano e menos de uma vez por mês & 2 \\
\hline & Média & Mais de 1 (uma) vez por mês e menos de uma vez por semana & 3 \\
\hline & Alta & Todos os dias & 4 \\
\hline \multirow{5}{*}{$\begin{array}{l}\text { Regime de } \\
\text { Emergência }\end{array}$} & $\begin{array}{l}\text { Altamente } \\
\text { Improvável }\end{array}$ & $\begin{array}{l}\text { Conceitualmente possível, mas extremamente improvável de } \\
\text { acontecer durante a vida útil do empreendimento. Não existe } \\
\text { referencial histórico de ocorrências. }\end{array}$ & 1 \\
\hline & Improvável & $\begin{array}{l}\text { Espera-se não acontecer durante a vida útil do empreendimento, } \\
\text { mas que possa ter ocorrido em algum lugar do mundo. }\end{array}$ & 2 \\
\hline & Pouco Provável & $\begin{array}{l}\text { Possível que ocorra poucas vezes durante a vida útil do } \\
\text { empreendimento. }\end{array}$ & 3 \\
\hline & Provável & $\begin{array}{l}\text { Espera-se ocorrer poucas vezes durante a vida útil do } \\
\text { empreendimento. }\end{array}$ & 4 \\
\hline & Esperado & $\begin{array}{l}\text { Espera-se que ocorra muitas vezes durante a vida útil do } \\
\text { empreendimento. }\end{array}$ & 5 \\
\hline
\end{tabular}


Quadro 2. Controle e percepção de risco associado ao perigo.

\begin{tabular}{|c|c|c|c|}
\hline & CATEGORIA & DESCRIÇÃO & PONTOS \\
\hline \multirow{4}{*}{ Controle } & Inexistente & $\begin{array}{l}\text { Não existe nenhum item de controle para redução ou eliminação } \\
\text { da probabilidade de ocorrência. }\end{array}$ & 3 \\
\hline & Deficiente & $\begin{array}{l}\text { Existência de item de controle parcial ou totalmente, mas que } \\
\text { sua falha possa provocar potencialização do risco. }\end{array}$ & 2 \\
\hline & Razoável & $\begin{array}{l}\text { Existência de item de controle que possibilite reduzir ou } \\
\text { eliminar a probabilidade de ocorrência do aspecto; a eficácia } \\
\text { de controle depende do fator humano, não eliminando e nem } \\
\text { reduzindo totalmente o risco. }\end{array}$ & 1 \\
\hline & Eficaz & $\begin{array}{l}\text { Existe item de controle e sua eficácia não depende do fator } \\
\text { humano para eliminar ou reduzir o risco. }\end{array}$ & 0 \\
\hline \multirow{4}{*}{ Percepção } & $\begin{array}{c}\text { Alta } \\
\text { Complexidade }\end{array}$ & $\begin{array}{l}\text { A percepção do risco relativo ao processo é identificada só por } \\
\text { pessoas com experiência e treinamento específico. }\end{array}$ & 3 \\
\hline & Complexa & $\begin{array}{l}\text { A percepção de risco relativo ao processo se percebe pela } \\
\text { avaliação da atividade, por pessoa que conheça o processo do } \\
\text { ponto de vista operacional e de segurança. }\end{array}$ & 2 \\
\hline & Razoável & $\begin{array}{l}\text { A percepção de risco relativo ao processo pode ser percebida por } \\
\text { qualquer indivíduo, mas necessita de treinamento simples. }\end{array}$ & 1 \\
\hline & Simples & $\begin{array}{l}\text { A percepção de risco relativo ao processo pode ser percebida por } \\
\text { qualquer indivíduo do empreendimento, independentemente de } \\
\text { treinamento ou conhecimento da atividade ou processo. }\end{array}$ & 0 \\
\hline
\end{tabular}

Fonte: Rego \& Lima (2006), com adaptações.

Quadro 3. Efeito e impacto, mitigação associada aos impactos e repercussão relativa ao dano.

\begin{tabular}{|c|c|c|c|}
\hline & CATEGORIA & DESCRIÇÃO & PONTOS \\
\hline \multirow{4}{*}{$\begin{array}{l}\text { Efeito e } \\
\text { impacto }\end{array}$} & Desprezível & $\begin{array}{l}\text { Lesões ou doença leves, com efeitos reversíveis levemente } \\
\text { prejudiciais. Exemplos: ferimentos leves, irritações leves, que não } \\
\text { impliquem afastamento superior a } 15 \text { dias. }\end{array}$ & 1 \\
\hline & $\begin{array}{l}\text { Levemente } \\
\text { Prejudicial }\end{array}$ & $\begin{array}{l}\text { Lesões ou doenças sérias, com efeitos reversíveis severos e } \\
\text { prejudiciais. Exemplo: irritações sérias, pneumoconiose não } \\
\text { fibrogênica, lesão reversível que implique afastamento superior a } \\
15 \text { dias. }\end{array}$ & 2 \\
\hline & Prejudicial & $\begin{array}{l}\text { Lesão ou doença crítica, com efeitos irreversíveis severos e } \\
\text { prejudiciais que podem limitar a capacidade funcional. Exemplo: } \\
\text { PAIRO, danos ao sistema nervoso central (SNC), lesões com } \\
\text { sequelas, que impliquem afastamento de longa duração ou } \\
\text { limitações da capacidade funcional. }\end{array}$ & 3 \\
\hline & $\begin{array}{l}\text { Extremamente } \\
\text { Prejudicial }\end{array}$ & $\begin{array}{l}\text { Lesão ou doença incapacitante ou fatal. Exemplo: perda de } \\
\text { membros ou órgãos que incapacitem definitivamente para o } \\
\text { trabalho, lesões múltiplas que resultem em morte, doenças } \\
\text { progressivas potencialmente fatais como pneumoconiose. }\end{array}$ & 4 \\
\hline \multirow{3}{*}{$\begin{array}{l}\text { Mitigação } \\
\text { associada } \\
\text { aos impactos }\end{array}$} & Deficiente & $\begin{array}{l}\text { Não existe item de controle para possibilitar redução ou } \\
\text { eliminação da potencialização do dano; existe um item de } \\
\text { controle, mas sua falta pode provocar a potencialização do dano. }\end{array}$ & 3 \\
\hline & Razoável & $\begin{array}{l}\text { Existe item de controle que possibilite redução ou eliminação } \\
\text { da potencialização do dano; a eficácia do controle depende } \\
\text { do fator humano, não eliminando nem reduzindo totalmente a } \\
\text { potencialização do dano. }\end{array}$ & 2 \\
\hline & Eficaz & $\begin{array}{l}\text { Existe item de controle que possibilite redução ou eliminação } \\
\text { da potencialização do dano; a eficácia do controle não depende } \\
\text { do fator humano, eliminando ou reduzindo totalmente a } \\
\text { potencialização do dano. }\end{array}$ & 1 \\
\hline \multirow{4}{*}{$\begin{array}{l}\text { Repercussão } \\
\text { relativa ao } \\
\text { dano }\end{array}$} & Ampla & $\begin{array}{l}\text { O alcance da repercussão relativa à imagem da empresa em } \\
\text { função do impacto sofrido é de âmbito nacional. }\end{array}$ & 3 \\
\hline & Parcial & $\begin{array}{l}\mathrm{O} \text { alcance da repercussão relativa à imagem da empresa em } \\
\text { função do impacto sofrido é de âmbito regional. }\end{array}$ & 2 \\
\hline & Local & $\begin{array}{l}\text { O alcance da repercussão relativa à imagem da empresa em } \\
\text { função do impacto sofrido é de âmbito local. }\end{array}$ & 1 \\
\hline & Interno & $\begin{array}{l}\text { O alcance da repercussão relativa à imagem da empresa em } \\
\text { função do impacto sofrido é de âmbito interno sem repercussão. }\end{array}$ & 0 \\
\hline
\end{tabular}


O critério adotado com o cruzamento dos fatores de risco associados aos perigos e fatores de riscos associados aos impactos, por meio da sua multiplicação, resultou na matriz de classificação de riscos segundo sua significância (Figura 3).

\subsection{Avaliação da tolerabilidade do risco}

Esta avaliação teve por objetivo determinar o grau de prioridade das ações, ou seja, quanto menor for a tolerabilidade do risco, significa dizer que a ação deve ser implementada de imediato ou a curto prazo, caso contrário, de médio a longo prazo. Para isso foi adotado o cruzamento dos fatores de risco associados ao perigo (Probabilidade) com os fatores de riscos associados aos impactos (Gravidade), conforme critério apresentado na Figura 3. Assim, quanto maior for o $\mathrm{n}^{\mathrm{o}}$ encontrado, menor é a tolerabilidade ao risco (Quadro 4).

\subsection{Plano de ação}

Pelas características prévias das empresas "A" e "B", e identificação, avaliação e controle dos fatores de riscos presentes nos respectivos locais de trabalho, foram priorizadas as ações conforme a criticidade do risco de acordo com a Matriz de Classificação do Risco. Foram levados em consideração os fatores associados aos perigos e suas consequências, havendo a identificação da gravidade dos riscos de acordo com o seu potencial e as medidas de controles existentes.
Para os riscos com classificação trivial e tolerável, o plano de ação previu a manutenção, por parte da empresa, dos controles existentes. Para os riscos com classificação moderado, substancial e intolerável foi proposta a adoção de medidas de controle, priorizando as ações do intolerável para o moderado.

\subsection{Critérios para avaliação quantitativa}

Depois de uma análise preliminar no ambiente de trabalho de cada empresa, observou-se que as atividades realizadas eram rotineiras. Pode-se considerar, então, que os processos eram repetitivos, do ponto de vista dos riscos existentes no ambiente de trabalho.

Assim, optou-se por realizar a coleta de dados durante 5 dias em cada empresa, período este suficiente para se verificar a rotina (habitual e permanente) funcional.

$\mathrm{Na}$ avaliação de exposição ocupacional ao ruído, foram utilizados os seguintes instrumentos: Dosímetro Digital (NoisePro DLX, Quest Technologies) e Calibrador Acústico (QC, Quest Technologies). O dosímetro foi configurado obedecendo aos critérios estabelecidos nos Anexos 01 e 02 da Norma Regulamentadora (NR) 15, (Brasil, 2011c), e os resultados obtidos foram comparados com os parâmetros estabelecidos na NR 9 (Brasil, 1994) e NR 15.

Para avaliação da exposição ocupacional ao calor, foram adotados os critérios legais estabelecidos no Anexo 03 da NR 15 (Brasil, 2011c) e os critérios técnicos da NHO 06 (Fundacentro, 2002). O equipamento utilizado foi o Termômetro de globo

\begin{tabular}{|c|c|c|c|c|c|c|c|c|c|}
\hline \multirow{11}{*}{ 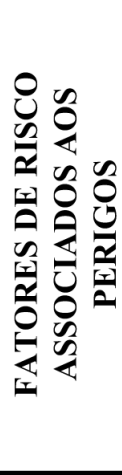 } & \multicolumn{9}{|c|}{ FATORES DE RISCO ASSOCIADOS AOS IMPACTOS } \\
\hline & & 3 & 4 & 5 & 6 & 7 & 8 & 9 & 10 \\
\hline & 3 & 9 & 12 & 15 & 18 & 21 & 24 & 27 & 30 \\
\hline & 4 & 12 & 16 & 20 & 24 & 28 & 32 & 36 & 40 \\
\hline & 5 & 15 & 20 & 25 & 30 & 35 & 40 & 45 & 50 \\
\hline & 6 & 18 & 24 & 30 & 36 & 42 & 48 & 54 & 60 \\
\hline & 7 & 21 & 28 & 35 & 42 & 49 & 56 & 63 & 70 \\
\hline & 8 & 24 & 32 & 40 & 48 & 56 & 64 & 72 & 80 \\
\hline & 9 & 27 & 36 & 45 & 54 & 63 & 72 & 81 & 90 \\
\hline & 10 & 30 & 40 & 50 & 60 & 70 & 80 & 90 & 100 \\
\hline & 11 & 33 & 44 & 55 & 66 & 77 & 88 & 99 & 110 \\
\hline
\end{tabular}

Figura 3. Matriz de Classificação do Risco. Fonte: Rego \& Lima (2006), com adaptações.

Quadro 4. Classificação de significância do risco.

\begin{tabular}{|c|c|c|c|}
\hline \multicolumn{2}{|c|}{ CLASSIFICAÇÃO DA SIGNIFICÂNCIA } & AÇÃO \\
\hline TRIVIAL & Até 24 & Não significativo & Manter as medidas de controle existentes \\
\hline TOLERÁVEL & De 25 a 49 & Significativo & $\begin{array}{c}\text { Sob controle, mas necessita de ações } \\
\text { administrativas }\end{array}$ \\
\hline MODERADO & De 50 a 72 & Significativo - nível 1 & Ação de médio prazo \\
\hline SUBSTANCIAL & De 77 a 90 & Significativo - nível 2 & Ação de curto prazo \\
\hline INTOLERÁVEL & De 99 a 110 & Significativo - nível 3 & Ação de imediato \\
\hline
\end{tabular}

Fonte: Rego \& Lima (2006), com adaptações. 
digital, (TGD 200, Instrutherm). O período de medição ocorreu na condição de sobrecarga térmica mais desfavorável da jornada de trabalho. Depois da medição, o resultado foi comparado com os limites estabelecidos pela legislação vigente, especificamente a Portaria $\mathrm{N}^{\mathrm{o}} 3.214$, de 8 de junho de 1978, NR 15 (Brasil, 2011c).

A avaliação e medição da iluminância foram realizadas segundo os critérios legais estabelecidos pela NR 17 (Brasil, 2007) e os critérios técnicos da Norma Brasileira NBR 5413, da Associação Brasileira de Normas Técnicas (ABNT, 1992). Para a medição, foi utilizado o instrumento Iluminancímetro, popularmente conhecido como Luxímetro (LX 102, Lutron). Os resultados encontrados foram comparados com o estabelecido na NR 17.

Observando os princípios éticos da pesquisa em atendimento à Resolução 196/96, item IV do Conselho Nacional de Saúde (Brasil, 1996) os participantes ou sujeitos da pesquisa foram devidamente esclarecidos quanto ao objetivo e finalidades do estudo, por meio do Termo de Consentimento Livre e Esclarecido e o Termo de Autorização. Desta forma, os dados coletados nas empresas tiveram finalidade estritamente científica.

\section{Resultados e discussão}

As empresas estão divididas basicamente em 3 (três) setores distintos: Administração, Produção e Expedição. O setor administrativo é construído por piso de material lavável, parede de alvenaria na cor branca, cobertura de PVC, iluminação mista (artificial e natural) e ventilação natural e artificial (climatizada). Esse ambiente é composto por mesas, computadores e armários.

Em ambas as empresas, as atividades dos setores de Administração e Expedição eram semelhantes, sendo assim os perigos, os impactos associados e a classificação dos riscos foram os mesmos. As atividades administrativas identificadas foram: digitação, preenchimento de formulário, emissão de nota fiscal, acompanhamento de pedidos, atendimento aos clientes, dentre outras atividades rotineiras de escritório. Os perigos identificados nas atividades desempenhadas neste setor estão relacionados à postura inadequada ao sentar (risco tolerável) e ao nível de iluminância no setor (risco trivial). As atividades identificadas no setor de expedição foram: carga e descarga do caminhão, cujos perigos identificados foram o transporte manual de carga (risco tolerável), queda ao subir e descer do caminhão (risco tolerável), além do perigo devido ao nível de ruído no ambiente, cujo risco foi considerado como trivial, por estar muito abaixo do limite de tolerância permitido.

No setor de produção das empresas "A" e "B", a cobertura do telhado é de zinco, com iluminação natural e artificial, piso de cimento polido, paredes de alvenaria e ventilação natural. Já na empresa "B", há, além da ventilação natural, a ventilação artificial por meio de ventiladores.

Na empresa "A", o setor de produção é composto por bancadas de mármore, carrinhos, mesa, fornos a gás, amassadeira, cilindro, empacotadeira, balança, assadeiras, armários, freezer, extrusora, fogão, tacho e pallets. Na empresa "B", o mesmo setor é composto por amassadeira, fogão com forno a gás e a lenha, pingadeira, bancadas, embaladeira, balança, cilindro, pallets, cilindro moldador, tacho, assadeiras e bandejas.

Na empresa "A", o setor de expedição é composto por bancada, balança, suporte, pallets e prateleira. Na empresa "B", este setor é composto por pallets e mesa. A descrição das atividades desenvolvidas nos setores de produção das empresas "A" e "B" encontram-se nos Quadros 5 e 6.

Nas empresas estudadas, pôde-se observar que os riscos no setor de produção estavam presentes desde a exposição à matéria-prima até o processo final de embalagem, pela associação das atividades com as condições das instalações e dos equipamentos. Na empresa "A", das 12 atividades avaliadas, foram identificados 58 riscos associados, cuja classificação resultou em 19 na categoria trivial (32,8\%); 22 na categoria tolerável (37,9\%); 15 na categoria moderado $(25,9 \%)$; e duas na categoria substancial $(3,4 \%)$. Na empresa "B", das 11 atividades avaliadas, foram identificados 68 riscos associados, cuja classificação resultou em 18 na categoria trivial (26,5\%); 27 na categoria tolerável $(39,7 \%) ; 13$ na categoria moderado $(19,1 \%)$; e 10 na categoria substancial $(14,7 \%)$. Não foram encontrados riscos classificados na categoria intolerável. Os resultados apresentados da identificação de perigos e avaliação de riscos por atividade nas empresas "A" e "B" (Quadros 7 e 8) não exibem os riscos classificados com significância na categoria trivial, cujo plano de ação indica que não há medida a ser implantada, apenas a manutenção e o controle das ações já existentes. Para as demais categorias de significância do risco, as empresas foram orientadas a adotar medidas de controle conforme o nível atingido. Desta forma, as ações recomendadas visam a eliminação ou a redução da significância dos riscos identificados.

Os riscos ocupacionais das empresas " $\mathrm{A}$ " $\mathrm{e}$ " $\mathrm{B}$ " foram dos tipos físicos, químicos, ergonômicos e de acidentes. Em consequência aos aspectos higiênico-sanitários seguidos pelas indústrias de alimentos, imprescindíveis para a segurança dos alimentos (Maia \& Rodrigues, 2012), não foram identificados riscos biológicos no setor de produção. Paralelamente, durante o período de levantamento dos dados, não foram evidenciados riscos químicos, e, em função da concentração, frequência, tempo de exposição e condições ambientais, não foi necessária a realização da avaliação quantitativa para esta categoria de risco. 
Quadro 5. Descrição das atividades do setor de produção da empresa "A".

\begin{tabular}{|c|c|}
\hline Atividade & Descrição \\
\hline Preparar a massa & $\begin{array}{l}\text { Adicionam-se os ingredientes na amassadeira, mistura-se até atingir a } \\
\text { homogeneidade, depois distribui-se a massa pronta nas bancadas. }\end{array}$ \\
\hline $\begin{array}{l}\text { Abrir (espalhar) a massa } \\
\text { na bancada }\end{array}$ & Com auxílio de um rolo abre-se a massa até atingir a espessura desejada. \\
\hline Cilindrar a massa & $\begin{array}{l}\text { Consiste em pegar a massa, colocá-la no cilindro, que a molda. Esse processo é } \\
\text { repetido por várias vezes, até atingir o "ponto desejado". }\end{array}$ \\
\hline $\begin{array}{l}\text { Preparar a massa para } \\
\text { congelamento }\end{array}$ & $\begin{array}{l}\text { Com auxílio de um rolo abre-se a massa, manualmente, põe-se o recheio, } \\
\text { enrolando-a em formato cilíndrico; envolve-se a massa no papel filme e a leva ao } \\
\text { freezer. }\end{array}$ \\
\hline $\begin{array}{l}\text { Cortar a massa congelada } \\
\text { (preparo do biscoito } \\
\text { "medalhão") }\end{array}$ & $\begin{array}{l}\text { A massa do freezer é colocada na bancada. Com auxílio de uma faca, corta-se a } \\
\text { massa no formato do biscoito, colocando-o na assadeira, que, depois de completa, é } \\
\text { posicionada no carrinho para ser levada ao forno. }\end{array}$ \\
\hline $\begin{array}{l}\text { Moldar os biscoitos } \\
\text { manualmente }\end{array}$ & $\begin{array}{l}\text { Retira-se uma pequena quantidade da massa que se encontra na bancada e, com } \\
\text { auxílio das duas mãos, molda-se o biscoito, que é, em seguida, colocado na } \\
\text { assadeira, que depois de completada, é posicionada no carrinho para ir ao forno. }\end{array}$ \\
\hline $\begin{array}{l}\text { Moldar os biscoitos na } \\
\text { extrusora }\end{array}$ & $\begin{array}{l}\text { A massa é abastecida no silo da máquina, automaticamente, passa pela extrusora } \\
\text { e adquire uma forma cilíndrica. Com auxílio de uma espátula, corta-se a massa } \\
\text { no tamanho estabelecido, que cai no cilindro moldador, para adquirir o formato } \\
\text { desejado, e que, na sequência, cai na bandeja. }\end{array}$ \\
\hline $\begin{array}{l}\text { Imar os biscoitos na } \\
\text { deira }\end{array}$ & $\begin{array}{l}\text { Consiste em pegar os biscoitos moldados na bandeja e arrumá-los na assadeira; } \\
\text { completada a assadeira, esta é colocada no carrinho para ser levada ao forno. }\end{array}$ \\
\hline Assar os biscoitos & $\begin{array}{l}\text { Consiste em levar os carrinhos com as assadeiras contendo os biscoitos moldados } \\
\text { até o forno. Depois do tempo de forno, que depende do tipo de biscoito, o forneiro } \\
\text { retira as assadeiras e as coloca em recipiente próprio para resfriamento. }\end{array}$ \\
\hline Fritar os biscoitos & $\begin{array}{l}\text { Consiste em pegar os biscoitos preparados e colocá-los na fritadeira com óleo } \\
\text { quente, na qual são virados até atingir o ponto. Com auxílio de um suporte, retiram- } \\
\text { se os biscoitos da fritadeira, colocando-os na bancada para resfriar. }\end{array}$ \\
\hline $\begin{array}{l}\text { Embalar os biscoitos } \\
\text { manualmente }\end{array}$ & $\begin{array}{l}\text { Com auxílio de uma concha, os biscoitos são colocados em suas embalagens, em } \\
\text { seguida, são pesados e armazenados para expedição. }\end{array}$ \\
\hline $\begin{array}{l}\text { Embalar os biscoitos com } \\
\text { auxílio de uma máquina } \\
\text { embaladeira }\end{array}$ & $\begin{array}{l}\text { Manualmente é abastecido o silo da máquina, posiciona-se a embalagem na saída } \\
\text { da máquina, automaticamente, e os biscoitos são embalados. Na sequência, a } \\
\text { embalagem é colocada na seladora para ser fechada e, posteriormente, levada para o } \\
\text { setor de expedição. }\end{array}$ \\
\hline
\end{tabular}

Em relação ao ruído, a maioria das atividades apresentou classificação de significância de risco tolerável, com nível de ruído abaixo do limite de tolerância de $80 \mathrm{~dB}(\mathrm{~A})$. Segundo a NR 9 (Brasil, 1994) para níveis de pressão sonora acima de $80 \mathrm{~dB}(\mathrm{~A})$, o trabalhador poderá sofrer pequenos danos (insônia, irritação e estresse). Assim, recomenda-se que a empresa inicie ações preventivas para a execução das atividades avaliadas a fim de atenuar os efeitos deste risco, com a utilização de protetor auricular que reduza em até $10 \mathrm{~dB}(\mathrm{~A})$ a exposição do trabalhador ao ruído, mesmo nas atividades classificadas com risco tolerável. A NR 15 (Brasil, 2011a) preconiza que com valores acima de $85 \mathrm{~dB}(\mathrm{~A})$, o trabalhador está exposto a uma atividade insalubre, cabendo de imediato ações por parte da empresa para eliminar ou minimizar os riscos (Figura 4).

$\mathrm{Na}$ empresa $\mathrm{B}$, na atividade de "Abastecer a fornalha do forno com lenha", foi identificada uma intensidade de $85,6 \mathrm{~dB}(\mathrm{~A})$, estando acima do limite de tolerância. A classificação do risco para esta atividade foi moderado, e o plano de ação consiste na redução do ruído na fonte, além do uso do protetor auricular que atenue em até $15 \mathrm{~dB}(\mathrm{~A})$ a intensidade de exposição, fazendo com que fique abaixo de $80 \mathrm{~dB}(\mathrm{~A})$.

Quanto à exposição ao calor, na empresa "A", não foram detectados valores acima do limite de tolerância preconizado pela NR 15 , os quais podem causar desidratação, hipo e hipertensão, cefaleia, dentre outros problemas. Já na empresa "B", nas atividades de assar biscoito (forno), cilindrar a massa, moldar o biscoito tipo pimentinha e fritar (fogão industrial), a intensidade verificada ficou acima do que preconiza a NR 15. Observa-se que este resultado apontado nas três últimas atividades está diretamente relacionado ao pouco espaço físico e às instalações, que não favorecem uma boa ventilação. Além dessas situações, há o fato de que a sala que abriga estas atividades está localizada na posição poente, recebendo, assim, o aquecimento proveniente da radiação solar a partir das 13 horas. Na atividade de assar biscoito, observou-se que a intensidade do calor é provocada 
Quadro 6. Descrição das atividades do setor de produção da empresa "B".

\begin{tabular}{|c|c|}
\hline Atividade & Descrição \\
\hline Derreter a manteiga & $\begin{array}{l}\text { A manteiga é colocada no tacho que se encontra no fogão, depois de derretida é } \\
\text { adicionada à massa que está na amassadeira. }\end{array}$ \\
\hline Preparar a massa & $\begin{array}{l}\text { Adicionam-se os ingredientes na amassadeira, que são misturados até atingir a } \\
\text { homogeneidade. Depois de pronta, a massa é distribuída nas bancadas e na máquina } \\
\text { denominada "pingadeira". }\end{array}$ \\
\hline $\begin{array}{l}\text { Moldar os biscoitos } \\
\text { manualmente }\end{array}$ & $\begin{array}{l}\text { A massa é colocada no "saco de confeitar" e, manualmente, é pressionada sobre } \\
\text { a assadeira, obtendo o formato e tamanho do biscoito. Completada, a assadeira é } \\
\text { colocada nos carrinhos para ser levada aos fornos. }\end{array}$ \\
\hline $\begin{array}{l}\text { Moldar os biscoitos na } \\
\text { máquina "pingadeira" }\end{array}$ & $\begin{array}{l}\text { A máquina é abastecida com a massa; na sequência, aciona-se a máquina por } \\
\text { pedal, automaticamente. A massa é moldada nas assadeiras, que são colocadas nos } \\
\text { carrinhos para serem levadas aos fornos. }\end{array}$ \\
\hline Assar os biscoitos & $\begin{array}{l}\text { Consiste em abastecer os carrinhos nos fornos e, após o tempo de cozimento, que } \\
\text { depende do tipo de biscoito, o forneiro retira as assadeiras e as coloca em caixotes } \\
\text { de madeira. }\end{array}$ \\
\hline Cilindrar a massa & $\begin{array}{l}\text { Consiste em pegar a massa e colocá-la no cilindro, no qual é moldada. Repetir este } \\
\text { processo por várias vezes até atingir o "ponto desejado da massa". }\end{array}$ \\
\hline $\begin{array}{l}\text { Moldar os biscoitos tipo } \\
\text { "pimentinha" }\end{array}$ & $\begin{array}{l}\text { A massa é colocada no cilindro moldador, que a molda e, na sequência, com auxílio } \\
\text { de uma faca, é cortada no tamanho desejado. }\end{array}$ \\
\hline Fritar os biscoitos & $\begin{array}{l}\text { Consiste em pegar os biscoitos preparados e colocá-los na fritadeira com óleo } \\
\text { quente, sendo virados, até atingir o ponto. Com auxílio de uma peneira metálica, os } \\
\text { biscoitos são retirados da fritadeira e colocados na bancada para resfriar. }\end{array}$ \\
\hline $\begin{array}{l}\text { Embalar os biscoitos } \\
\text { manualmente }\end{array}$ & $\begin{array}{l}\text { Com auxílio de uma concha, os biscoitos são colocados em suas embalagens e, em } \\
\text { seguida, pesados e armazenados para expedição. }\end{array}$ \\
\hline $\begin{array}{l}\text { Embalar os biscoitos com } \\
\text { auxílio de uma máquina } \\
\text { embaladeira }\end{array}$ & $\begin{array}{l}\text { Manualmente abastece-se o silo da máquina, posiciona-se a embalagem na saída } \\
\text { da máquina, automaticamente, e os biscoitos são embalados. Na sequência, a } \\
\text { embalagem é colocada na seladora para ser fechada e, posteriormente, levada para o } \\
\text { setor de expedição. }\end{array}$ \\
\hline $\begin{array}{l}\text { Abastecer a fornalha do } \\
\text { forno com lenha }\end{array}$ & Manualmente, a lenha é retirada do estoque e colocada na fornalha. \\
\hline
\end{tabular}

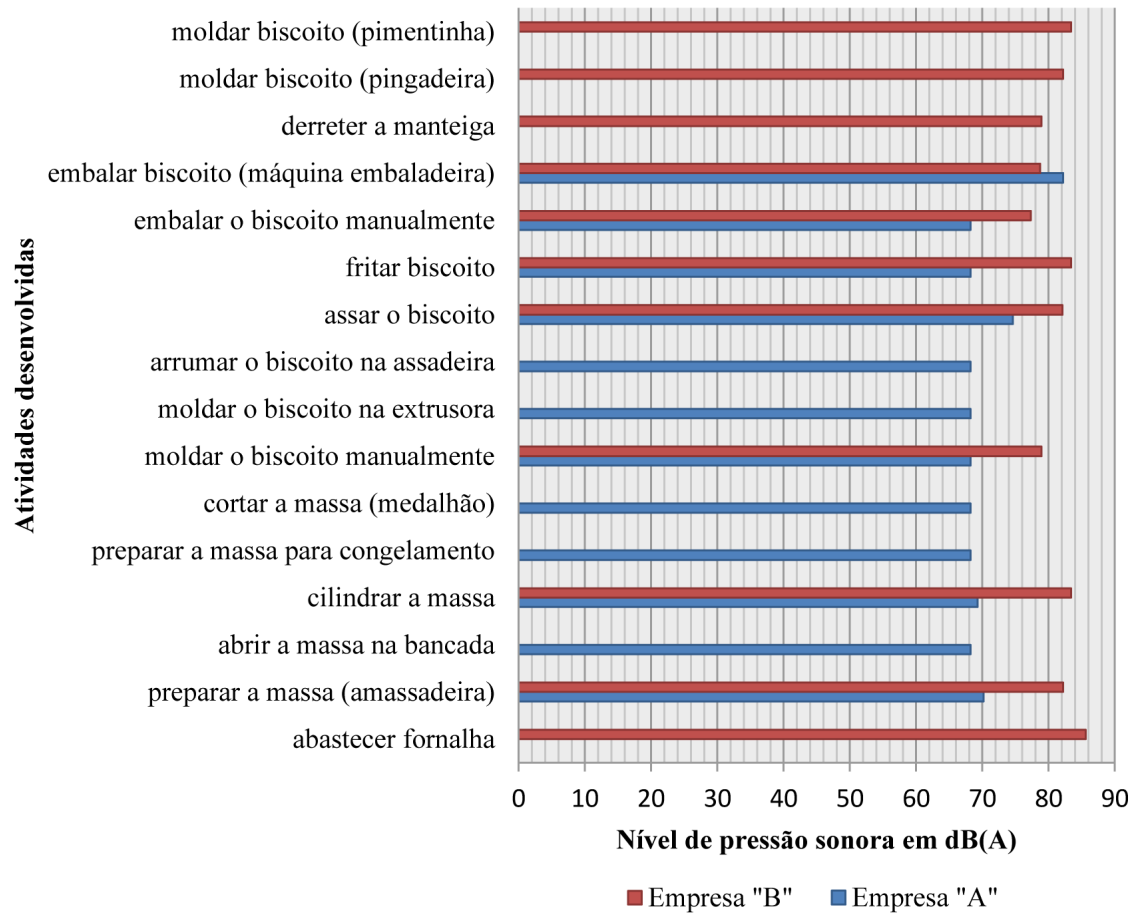

Figura 4. Nível de pressão sonora (em dB(A)) nas empresas "A" e "B". Fonte: Dados da pesquisa. Os índices em 0 indicam ausência da atividade na empresa. 


\begin{tabular}{|c|c|c|c|c|c|c|}
\hline 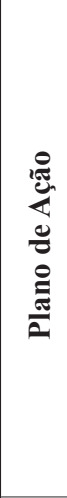 & 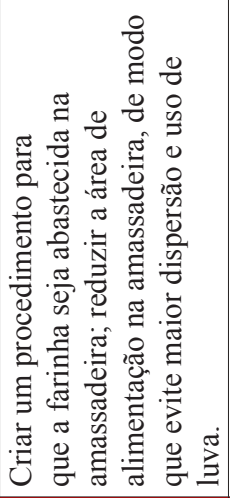 & 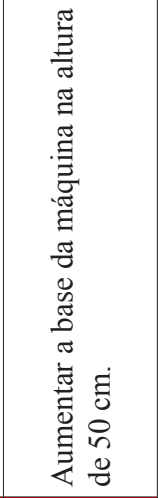 & 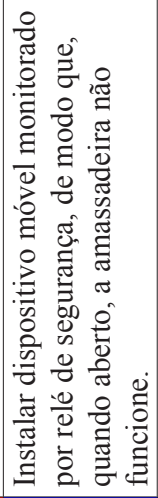 & 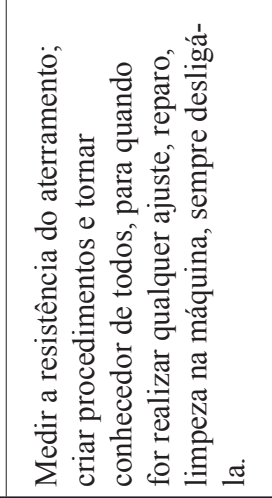 & 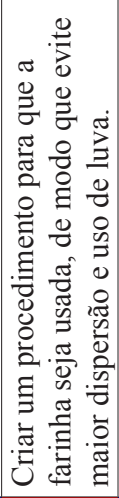 & 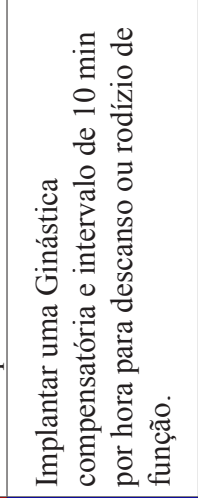 \\
\hline 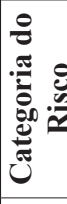 & $\begin{array}{l}\bar{\Xi} \\
\frac{\bar{\pi}}{0} \\
\frac{0}{0}\end{array}$ & $\begin{array}{l}\overrightarrow{0} \\
\frac{\vec{U}}{0} \\
\frac{0}{0}\end{array}$ & & & $\overline{0}$ & \\
\hline$a$ & F & 우 & $i$ & 8 & ชั & in \\
\hline$\tilde{\kappa}$ & 0 & in & $r$ & $a$ & 6 & 6 \\
\hline$\simeq$ & - & 0 & - & $\sim$ & - & 0 \\
\hline$\Sigma$ & $m$ & $m$ & $m$ & $m$ & $n$ & $n$ \\
\hline 되 & $\sim$ & $\sim$ & m & $\nabla$ & $N$ & $n$ \\
\hline $\bar{n}$ & r & $\infty$ & $\infty$ & $r$ & 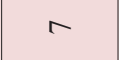 & $a$ \\
\hline 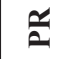 & 0 & - & - & - & 0 & $\sim$ \\
\hline u & $m$ & $m$ & $m$ & $N$ & $m$ & $m$ \\
\hline 工工 & + & $\nabla$ & $\nabla$ & $\nabla$ & $\nabla$ & $\nabla$ \\
\hline$\frac{1}{\mathrm{y}}$ & z & z & z & z & z & z \\
\hline $\begin{array}{l}\stackrel{\Xi}{E} \\
\text { ڤn }\end{array}$ & 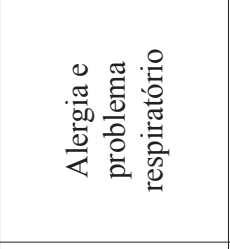 & 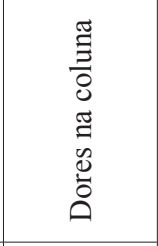 & 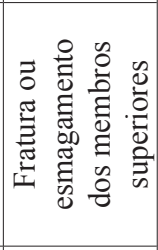 & 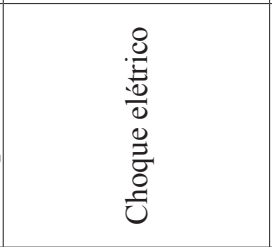 & 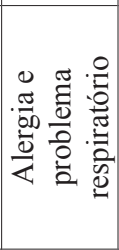 & 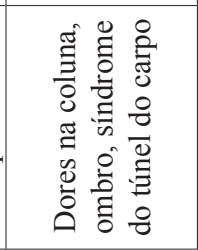 \\
\hline 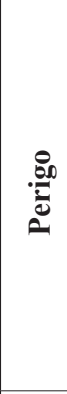 & 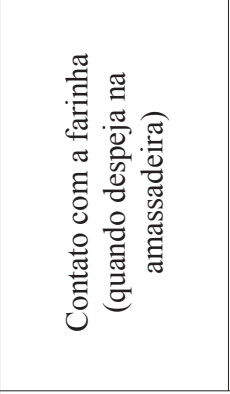 & 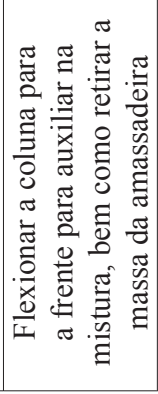 & 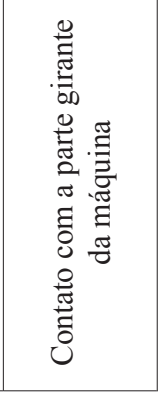 & 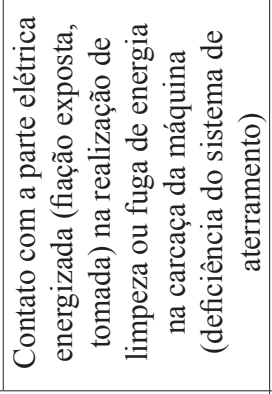 & 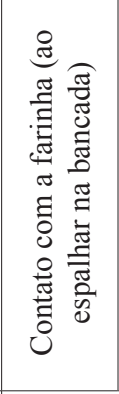 & 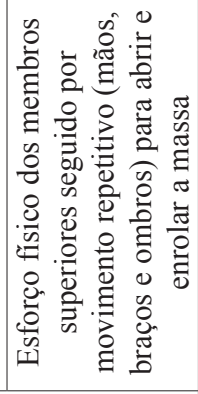 \\
\hline 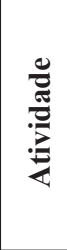 & & & 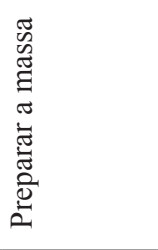 & & & 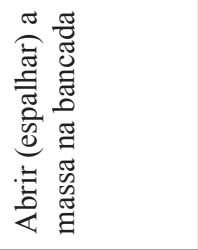 \\
\hline
\end{tabular}




\begin{tabular}{|c|c|c|c|c|c|c|c|c|}
\hline 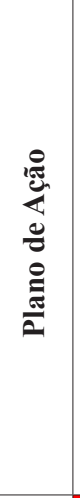 & 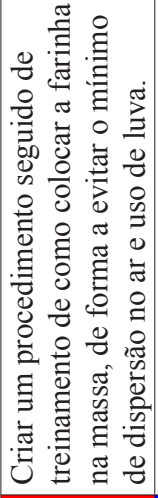 & 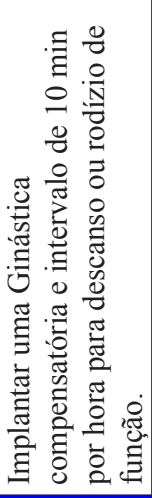 & 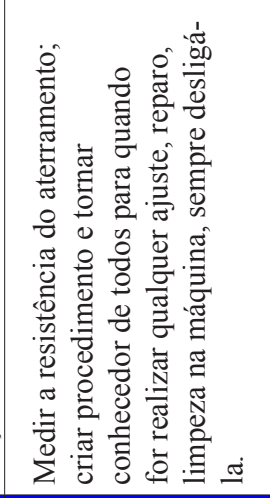 & 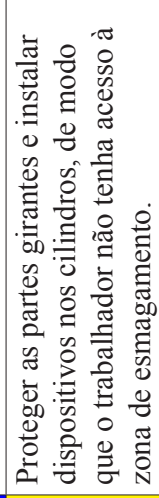 & 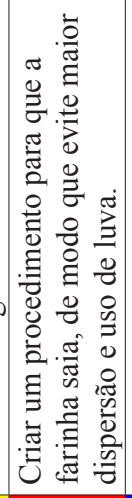 & 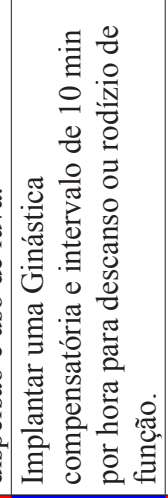 & 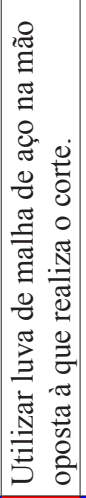 & 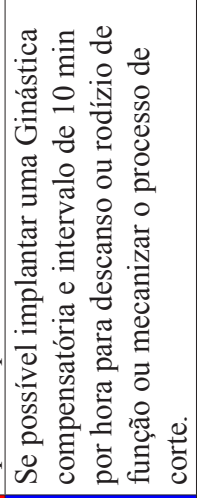 \\
\hline 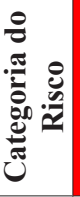 & $\begin{array}{l}\overline{0} \\
\frac{\pi}{0} \\
\frac{0}{0} \\
\qquad\end{array}$ & & & 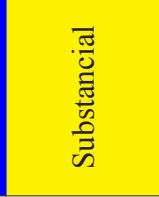 & 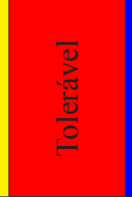 & & $\overline{0}$ & \\
\hline$a$ & F & in & 8 & $\infty$ & F & in & $\stackrel{\infty}{\sim}$ & in \\
\hline బี & 0 & 0 & $a$ & $ㅇ$ & 0 & 0 & $\nabla$ & 6 \\
\hline$\simeq$ & - & 0 & N & $m$ & - & 0 & 0 & 0 \\
\hline$\Sigma$ & $m$ & $m$ & $m$ & $m$ & $m$ & $m$ & $m$ & $m$ \\
\hline 되 & $N$ & $m$ & $\nabla$ & $\nabla$ & $N$ & $m$ & - & $m$ \\
\hline $\bar{\omega}$ & $r$ & $a$ & $r$ & $\infty$ & $r$ & $a$ & $r$ & $a$ \\
\hline$\stackrel{a}{E}$ & 0 & $N$ & - & - & 0 & $N$ & 0 & $N$ \\
\hline 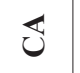 & $m$ & $m$ & $N$ & m & m & $m$ & $m$ & $m$ \\
\hline 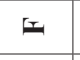 & $\nabla$ & $\nabla$ & $\nabla$ & $\nabla$ & $\nabla$ & $\nabla$ & $\nabla$ & $\nabla$ \\
\hline $\mathrm{x}_{\mathbf{Z}}^{\mathrm{x}}$ & z & Z & z & Z & Z & Z & Z & z \\
\hline 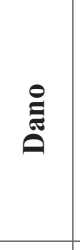 & 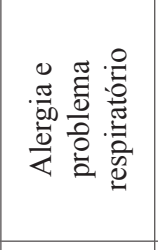 & 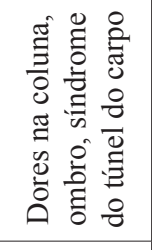 & 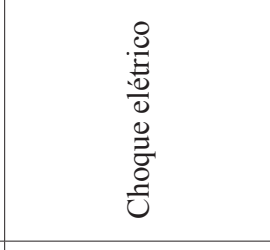 & 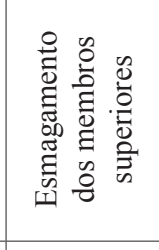 & 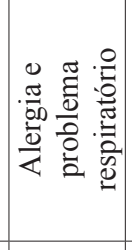 & 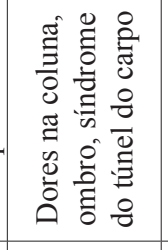 & ن் & 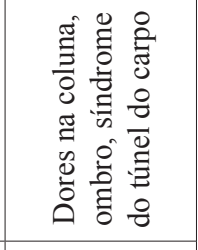 \\
\hline 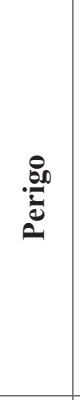 & 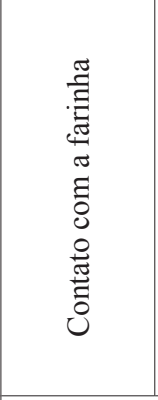 & 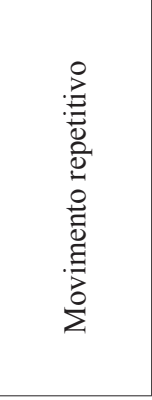 & 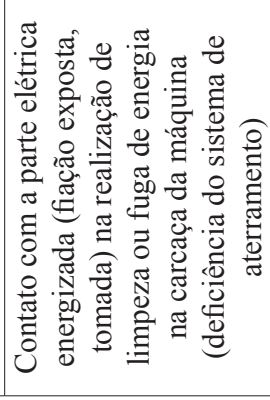 & 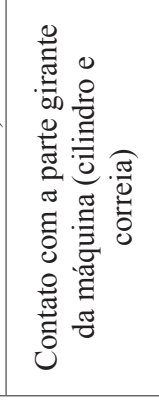 & 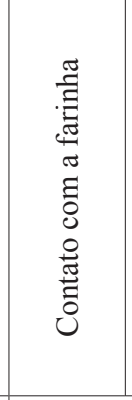 & 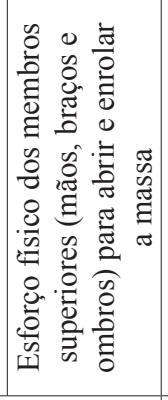 & 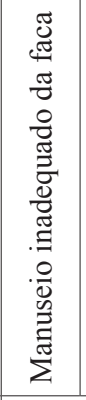 & 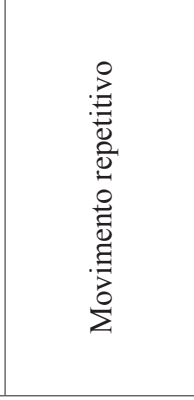 \\
\hline$\frac{0}{2}$ & & & 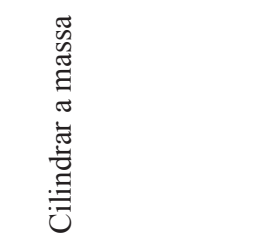 & & & 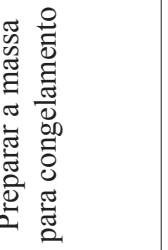 & స్ & 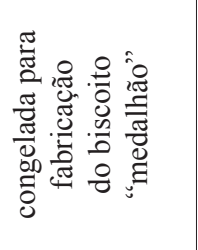 \\
\hline
\end{tabular}




\begin{tabular}{|c|c|c|c|c|c|c|}
\hline 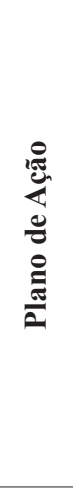 & 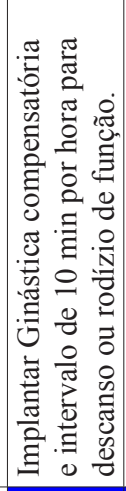 & 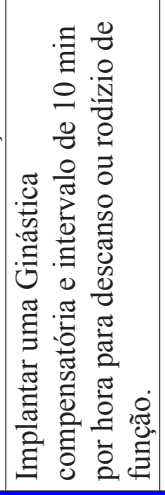 & 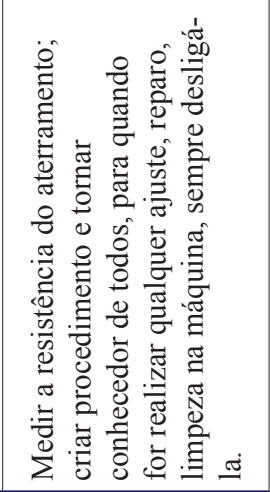 & 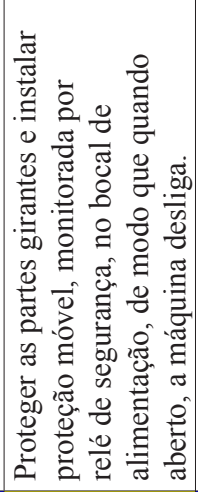 & 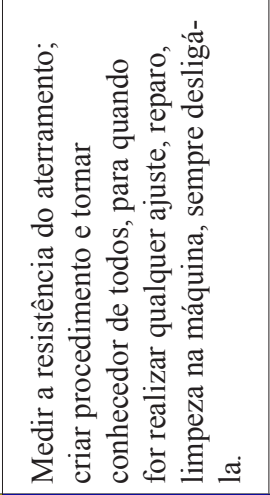 & 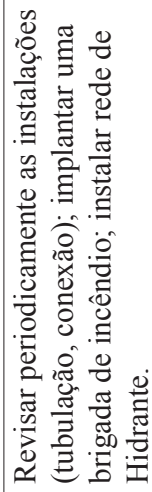 \\
\hline 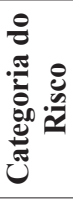 & & & & 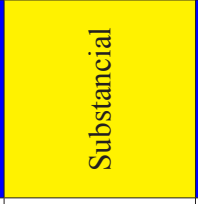 & & \\
\hline$a$ & in & in & $\widehat{6}$ & $\infty$ & $\widehat{6}$ & $\widehat{6}$ \\
\hline బ้ & 0 & 6 & $a$ & 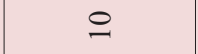 & $a$ & $a$ \\
\hline$\simeq$ & 0 & 0 & $\sim$ & $m$ & $\sim$ & $\sim$ \\
\hline$\Sigma$ & $m$ & $m$ & $m$ & $n$ & $m$ & $m$ \\
\hline 되 & $n$ & $m$ & $\nabla$ & $\nabla$ & $\nabla$ & $\nabla$ \\
\hline $\bar{n}$ & $a$ & $a$ & $r$ & $\infty$ & $r$ & $r$ \\
\hline$\stackrel{\text { a }}{\underline{a}}$ & $\sim$ & $\sim$ & - & - & - & 0 \\
\hline U & $m$ & $m$ & $N$ & $m$ & $N$ & $m$ \\
\hline I & $\nabla$ & $\nabla$ & $\nabla$ & $\nabla$ & $\nabla$ & $\nabla$ \\
\hline$\frac{5 x}{z}$ & z & z & z & z & z & z \\
\hline $\begin{array}{l}\stackrel{\Xi}{\tilde{E}} \\
\stackrel{\tilde{I}}{2}\end{array}$ & 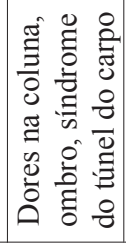 & 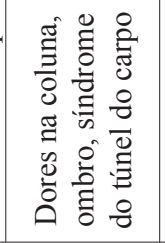 & 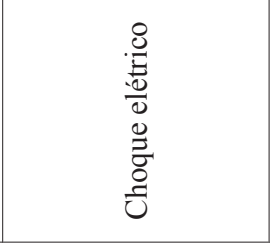 & 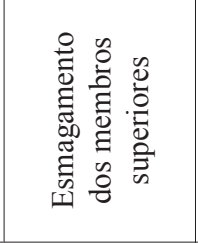 & 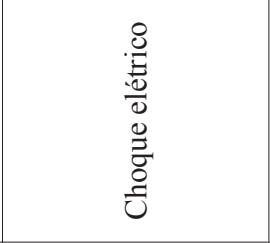 & 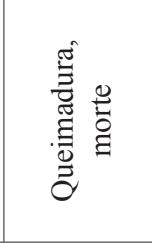 \\
\hline 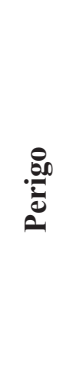 & 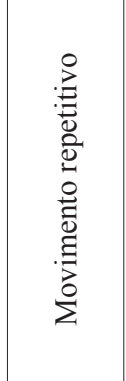 & 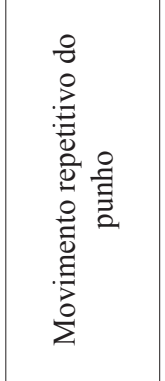 & 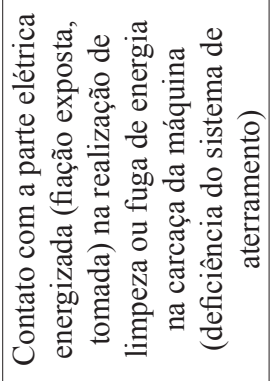 & 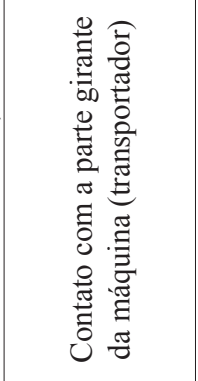 & 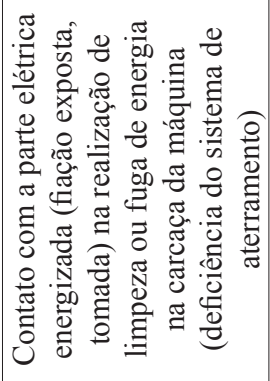 & 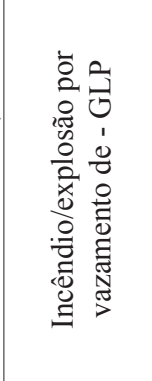 \\
\hline 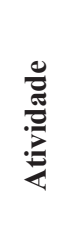 & 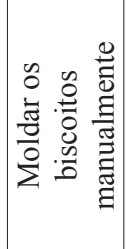 & & 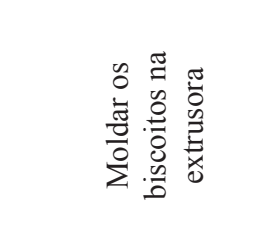 & & 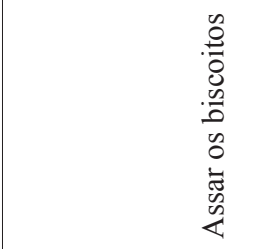 & \\
\hline
\end{tabular}




\begin{tabular}{|c|c|c|c|c|c|c|c|c|c|}
\hline 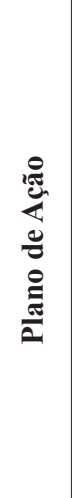 & 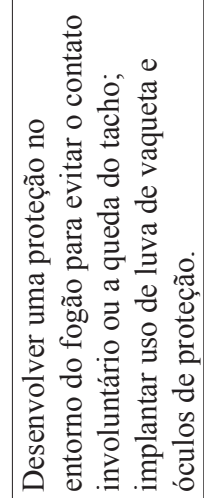 & 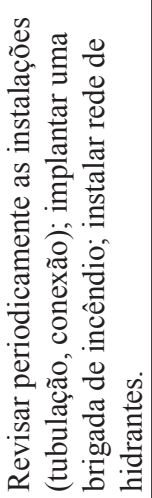 & 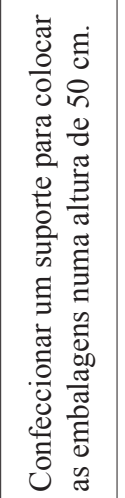 & 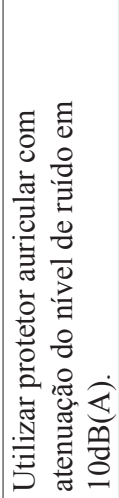 & 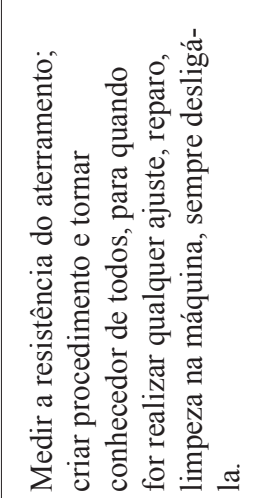 & 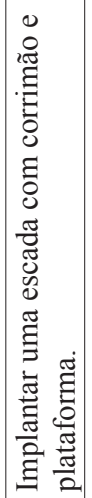 & 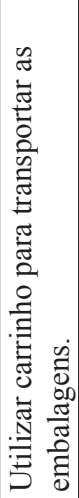 & 总 & 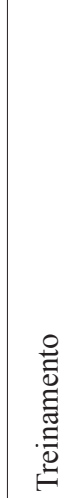 \\
\hline 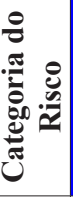 & & & & $\stackrel{0}{0}$ & & 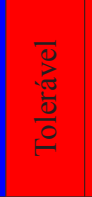 & 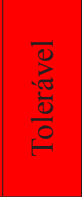 & 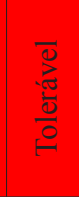 & $\begin{array}{l}\overline{0} \\
\frac{\pi}{0} \\
\frac{0}{0}\end{array}$ \\
\hline a & 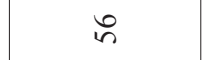 & $\tilde{6}$ & లె & $\stackrel{\infty}{\sim}$ & $\hat{6}$ & $\approx$ & $\stackrel{\sim}{\sim}$ & $\ddot{m}$ & $\stackrel{\infty}{\sim}$ \\
\hline$\tilde{\alpha}$ & $r$ & $a$ & 0 & $\nabla$ & $a$ & $\nabla$ & $\nabla$ & in & $\nabla$ \\
\hline$\simeq$ & - & $\sim$ & 0 & 0 & N & - & 0 & 0 & 0 \\
\hline$\Sigma$ & $m$ & $m$ & $m$ & m & m & 0 & $m$ & $n$ & $n$ \\
\hline 되 & $m$ & $\nabla$ & $m$ & - & $\nabla$ & $m$ & - & $\sim$ & - \\
\hline $\bar{n}$ & $\infty$ & $r$ & $\infty$ & $r$ & $r$ & $\infty$ & $r$ & $r$ & $r$ \\
\hline$\frac{a}{a}$ & - & 0 & - & - & - & - & - & 0 & - \\
\hline 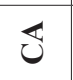 & m & $m$ & m & $\sim$ & $\sim$ & $m$ & $\sim$ & $n$ & $\sim$ \\
\hline LI & $\nabla$ & $\nabla$ & $\nabla$ & $\nabla$ & $\nabla$ & $\nabla$ & $\nabla$ & 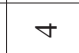 & $\forall$ \\
\hline 窔 & z & z & z & z & z & Z & Z & $\mathrm{z}$ & z \\
\hline ڤ & 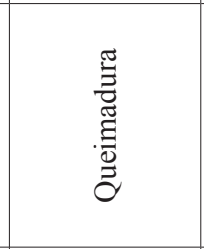 & 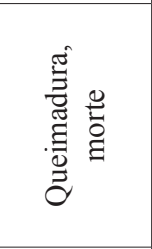 & 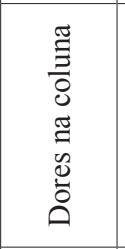 & 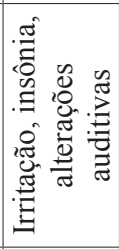 & 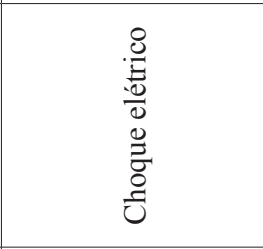 & 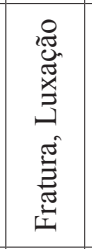 & 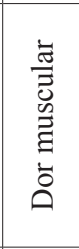 & 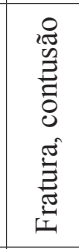 & 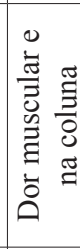 \\
\hline 兽 & 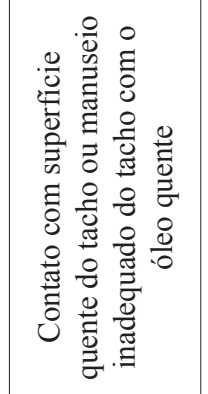 & 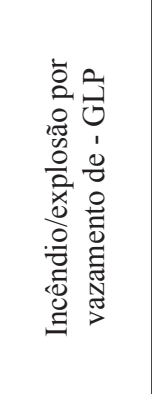 & 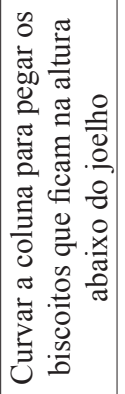 & 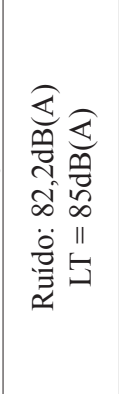 & 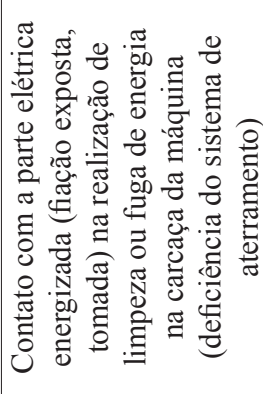 & 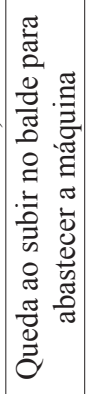 & 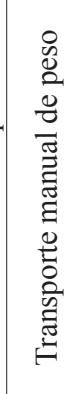 & 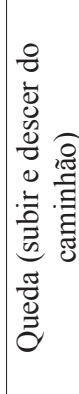 & 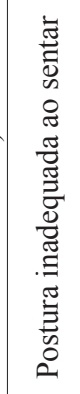 \\
\hline 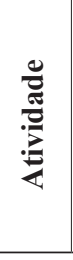 & 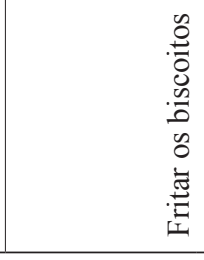 & & 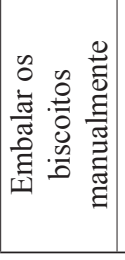 & & 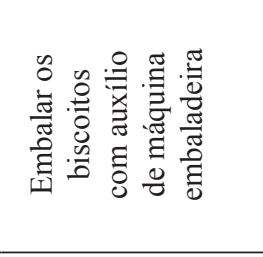 & & 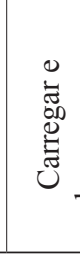 & 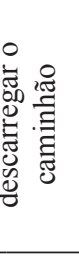 & 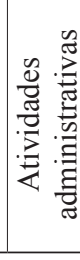 \\
\hline
\end{tabular}




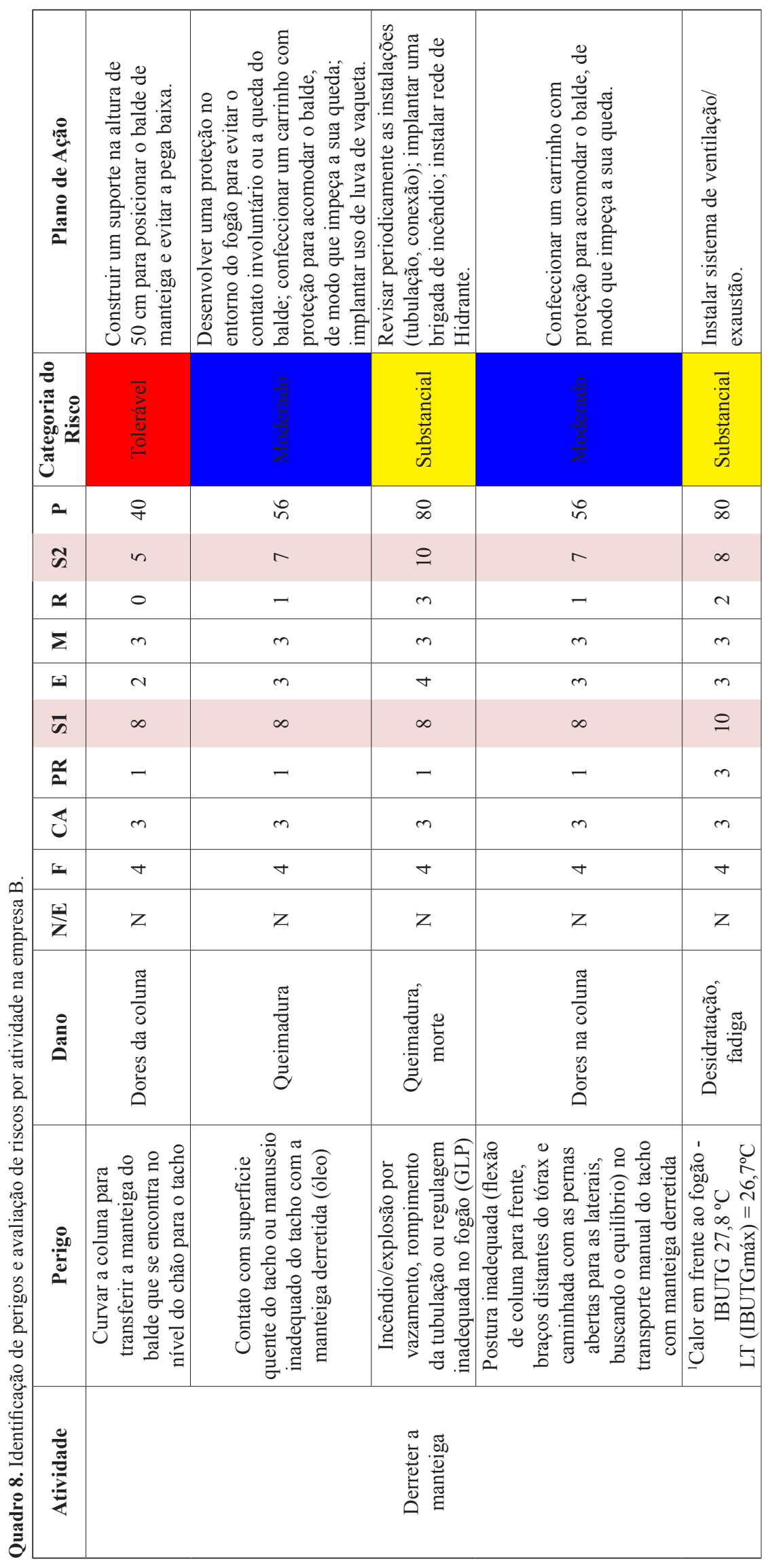




\begin{tabular}{|c|c|c|c|c|c|}
\hline 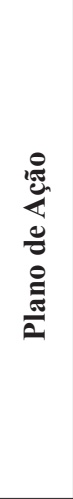 & 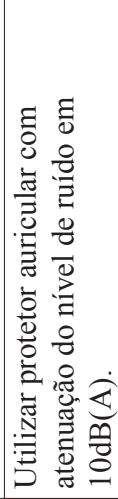 & 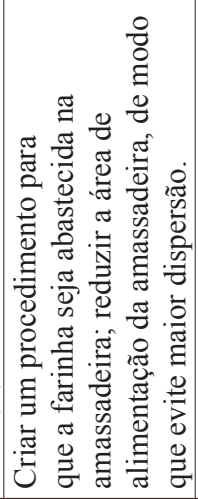 & 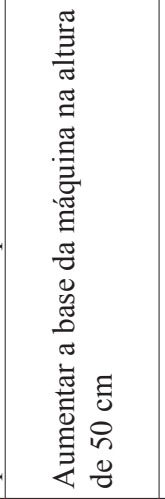 & 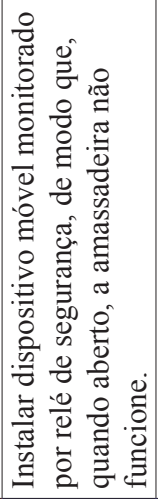 & 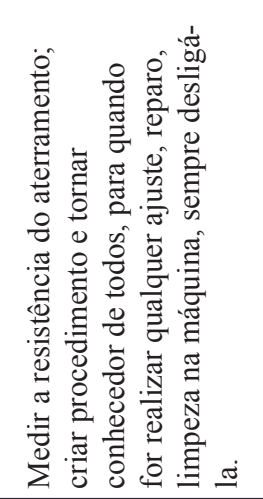 \\
\hline 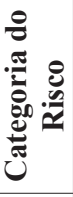 & $\ominus$ & $\begin{array}{l}\overline{0} \\
\frac{\vec{d}}{0} \\
\frac{0}{0}\end{array}$ & $\stackrel{0}{\circ}$ & & \\
\hline A & $\stackrel{\infty}{\sim}$ & F & 우 & 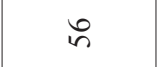 & $\tilde{6}$ \\
\hline ஜ & $\nabla$ & 0 & in & $r$ & $a$ \\
\hline$\simeq$ & 0 & - & 0 & - & N \\
\hline$\Sigma$ & $m$ & $m$ & $m$ & $m$ & $m$ \\
\hline tra & - & $N$ & N & $m$ & $\nabla$ \\
\hline $\bar{\omega}$ & $r$ & $r$ & $\infty$ & $\infty$ & $r$ \\
\hline 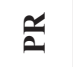 & - & 0 & - & - & - \\
\hline 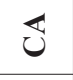 & 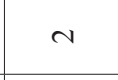 & $m$ & $m$ & $m$ & N \\
\hline 工 & $\nabla$ & $\nabla$ & $\nabla$ & $\nabla$ & $\nabla$ \\
\hline$\frac{\text { ry }}{\mathbf{z}}$ & Z & Z & Z & Z & Z \\
\hline 气 & 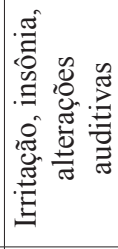 & 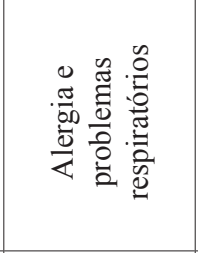 & 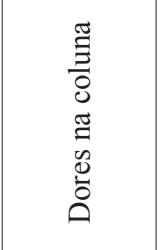 & 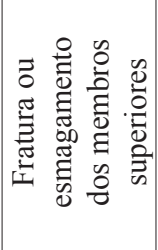 & 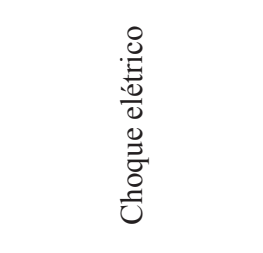 \\
\hline 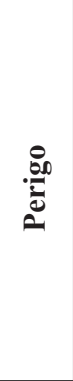 & 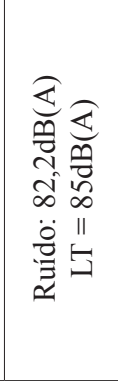 & 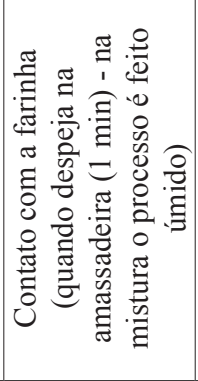 & 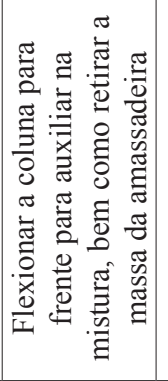 & 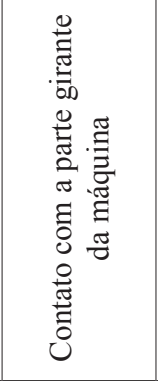 & 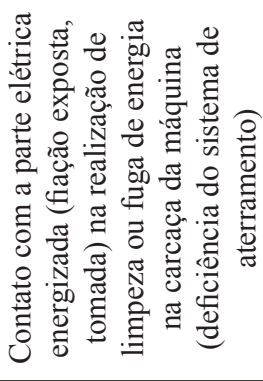 \\
\hline 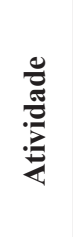 & & & 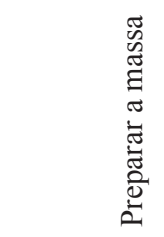 & & \\
\hline
\end{tabular}




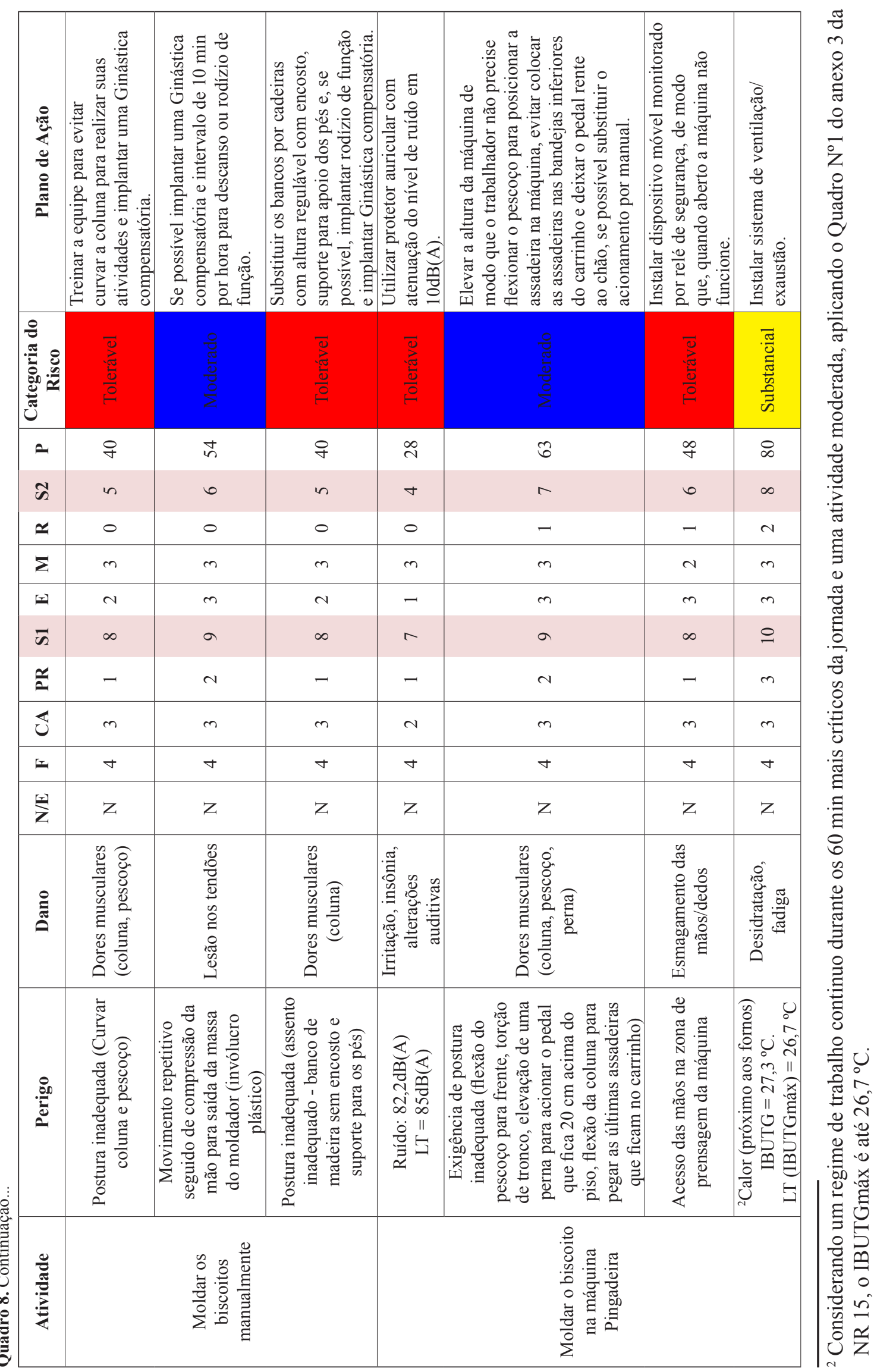




\begin{tabular}{|c|c|c|c|c|}
\hline 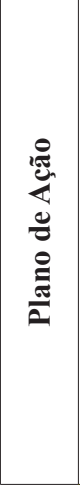 & 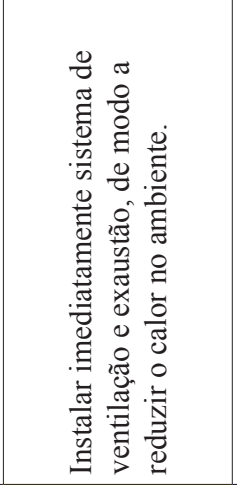 & 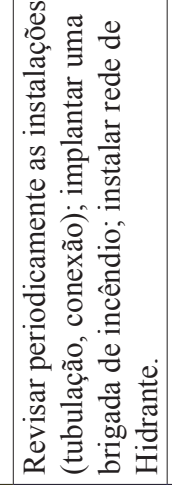 & 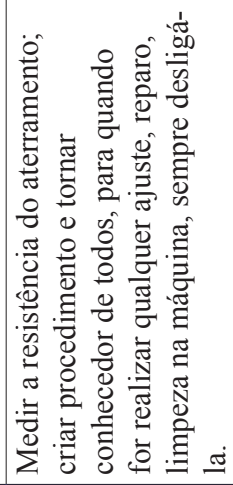 & 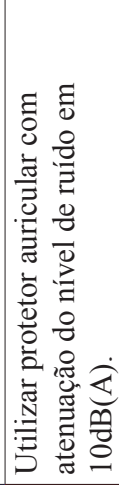 \\
\hline 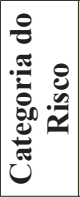 & 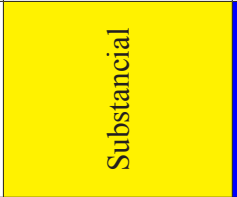 & & & $\frac{\sum_{0}^{\frac{\pi}{0}}}{\frac{\pi}{0}}$ \\
\hline$a$ & $\infty$ & 8 & 6 & $\stackrel{\infty}{\sim}$ \\
\hline ๙ื & $\infty$ & $a$ & $a$ & $\nabla$ \\
\hline$\simeq$ & $\sim$ & N & N & 0 \\
\hline$\Sigma$ & $m$ & $m$ & $m$ & $m$ \\
\hline 되 & $m$ & $\nabla$ & $\nabla$ & - \\
\hline $\bar{n}$ & $\stackrel{-}{ }$ & $\sim$ & $r$ & $\sim$ \\
\hline 孚 & $n$ & 0 & - & - \\
\hline త্ & $m$ & $m$ & $N$ & $N$ \\
\hline I & $\nabla$ & $\nabla$ & $\nabla$ & $\nabla$ \\
\hline 禾 & Z & Z & Z & Z \\
\hline ڤ્犬 & 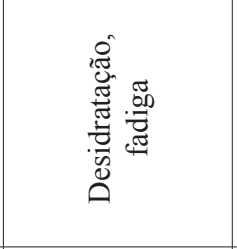 & 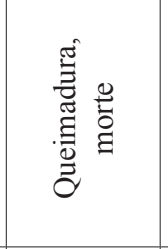 & 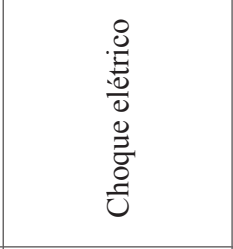 & 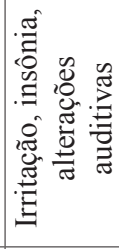 \\
\hline 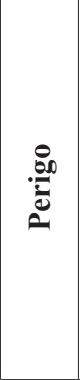 & 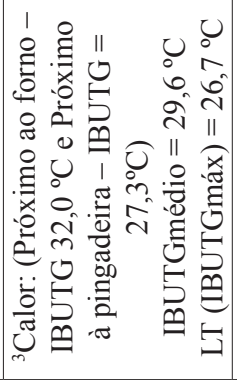 & 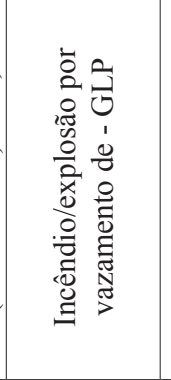 & 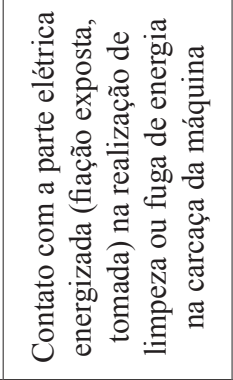 & 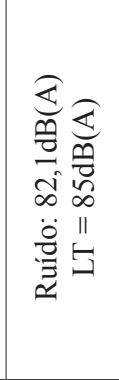 \\
\hline 总 & & $\begin{array}{l}0 \\
0 \\
0 \\
0 \\
0 \\
0 \\
0 \\
0\end{array}$ & & \\
\hline
\end{tabular}

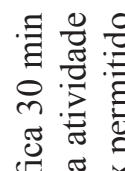

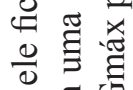
ชิ 胥 艺 is 0 范至 n 乙造兄 包 00 :

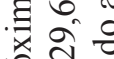
근 훈

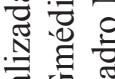
స్ 응응 은 O छ. 핀 ¿ 8 舫 믈 ฮั 을 $m$ 웅 을 氶 용 娄 음 ㄴ ข 용

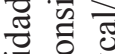
- U 응 (๘) 리 . 斊音 हี 일 음 응 응 tิ 0 율 웅 矛造 n 융 정 


\begin{tabular}{|c|c|c|c|c|c|c|}
\hline 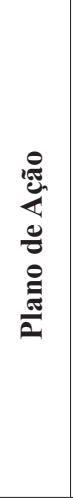 & 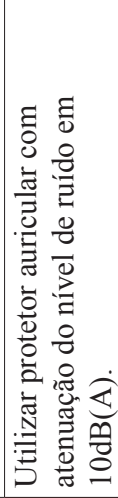 & 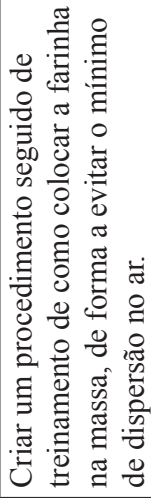 & 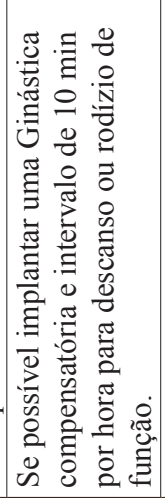 & 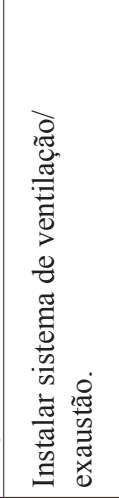 & 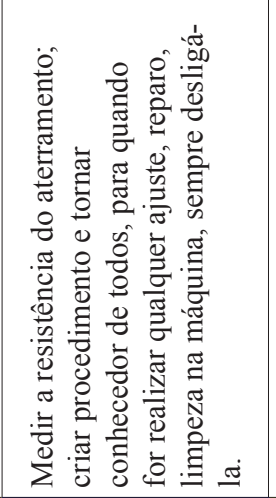 & 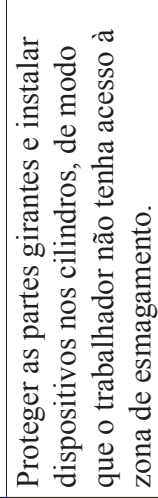 \\
\hline 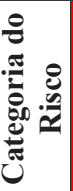 & $\Leftarrow$ & 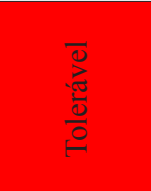 & 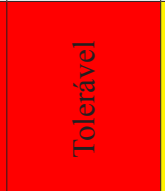 & 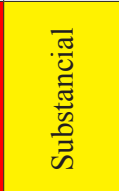 & & 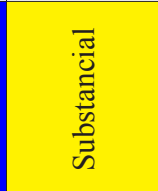 \\
\hline$a$ & $\stackrel{\infty}{\sim}$ & F & 우 & $\infty$ & $\widehat{6}$ & $\triangleright$ \\
\hline \% & $\nabla$ & 6 & in & $\infty$ & $a$ & $ㅇ$ \\
\hline$\simeq$ & 0 & - & 0 & N & N & $m$ \\
\hline$\Sigma$ & $m$ & $m$ & $m$ & $m$ & $m$ & $m$ \\
\hline r & - & $\mathrm{N}$ & N & $m$ & $\nabla$ & $\nabla$ \\
\hline $\bar{n}$ & $r$ & $r$ & $\infty$ & 으 & $r$ & $\infty$ \\
\hline$\stackrel{a}{*}$ & - & 0 & - & $m$ & - & - \\
\hline $\mathbb{U}$ & 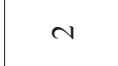 & $m$ & $m$ & $m$ & $N$ & $m$ \\
\hline 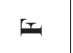 & $\nabla$ & $\nabla$ & $\nabla$ & $\nabla$ & $\nabla$ & $\nabla$ \\
\hline 臬 & Z & Z & Z & Z & Z & Z \\
\hline ฏ & 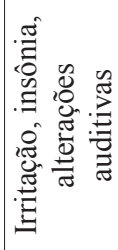 & 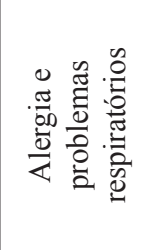 & 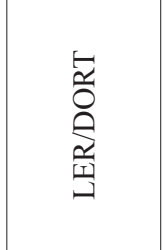 & 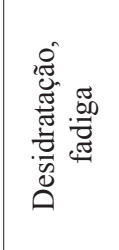 & 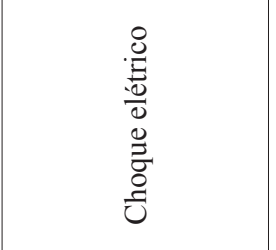 & 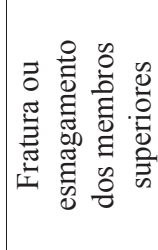 \\
\hline 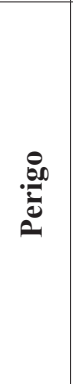 & 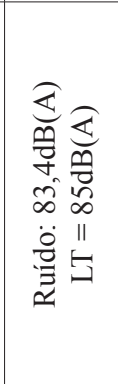 & 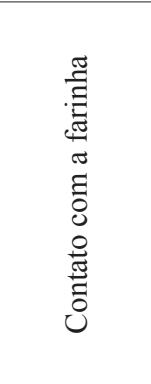 & 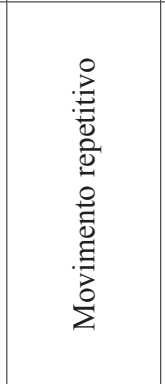 & 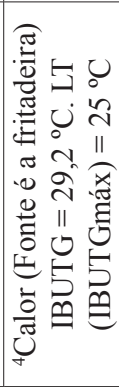 & 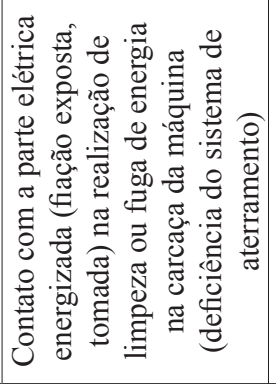 & 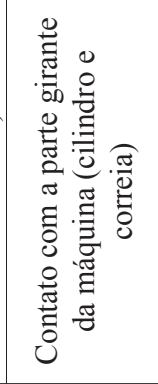 \\
\hline 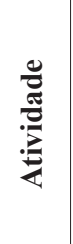 & & & & 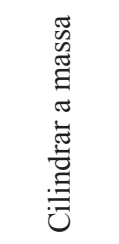 & & \\
\hline
\end{tabular}




\begin{tabular}{|c|c|c|c|c|c|c|c|}
\hline 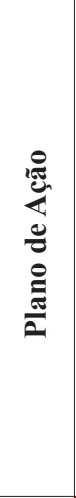 & 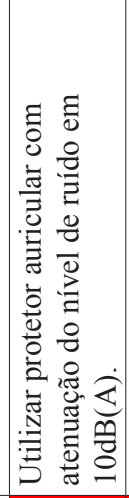 & 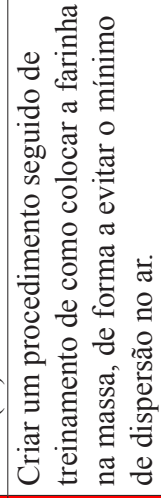 & 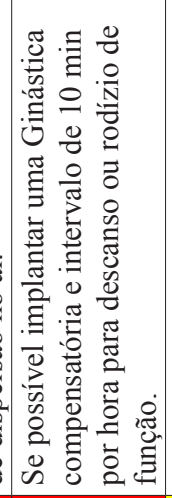 & 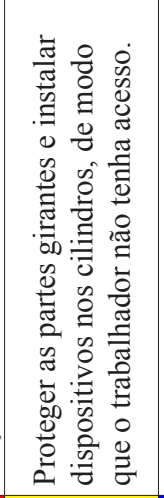 & 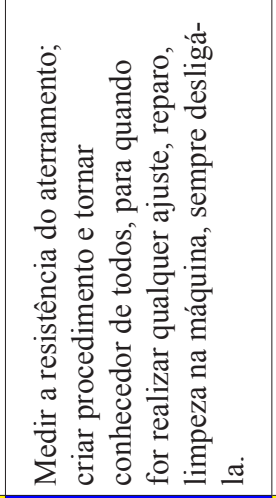 & 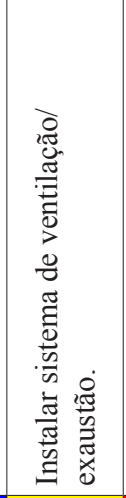 & 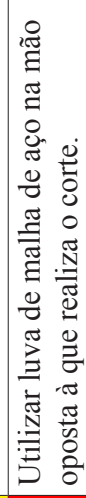 \\
\hline 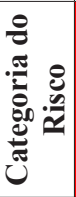 & 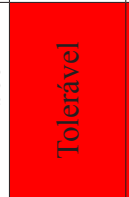 & $\begin{array}{l}\frac{\overrightarrow{0}}{\pi} \\
\frac{\pi}{0} \\
\frac{0}{0}\end{array}$ & 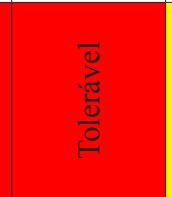 & 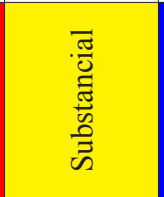 & & 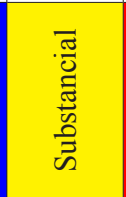 & \\
\hline$a$ & $\stackrel{\infty}{\sim}$ & F & f & $\triangleright$ & $\hat{6}$ & $\triangleright$ & $\stackrel{\infty}{\sim}$ \\
\hline ๘ै & $\nabla$ & 0 & in & 으 & $a$ & $\infty$ & $\nabla$ \\
\hline$\simeq$ & 0 & - & 0 & $m$ & $\sim$ & $\sim$ & 0 \\
\hline$\Sigma$ & $m$ & $m$ & $m$ & $m$ & $m$ & $m$ & $m$ \\
\hline 되 & - & N & N & $\nabla$ & $\nabla$ & $m$ & - \\
\hline $\bar{\omega}$ & $r$ & $r$ & $\infty$ & $\infty$ & - & 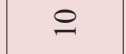 & $r$ \\
\hline$\stackrel{\underline{A}}{a}$ & - & 0 & - & - & - & $n$ & 0 \\
\hline U & $\sim$ & $m$ & $n$ & $m$ & $\sim$ & $m$ & $m$ \\
\hline I & $\nabla$ & $\nabla$ & $\nabla$ & $\nabla$ & $\nabla$ & $\nabla$ & $\nabla$ \\
\hline 空 & Z & z & Z & Z & Z & Z & Z \\
\hline & 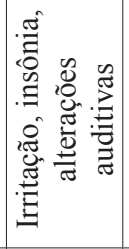 & 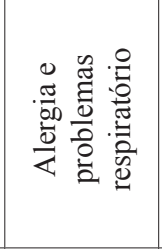 & 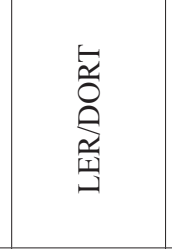 & 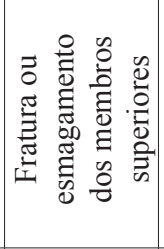 & 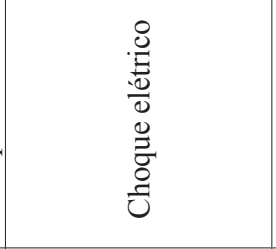 & 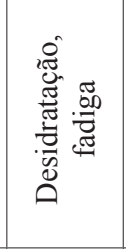 & نัّ \\
\hline 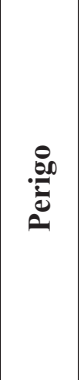 & 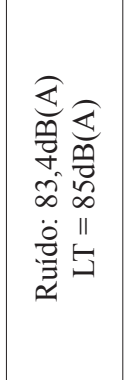 & 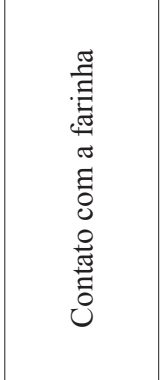 & 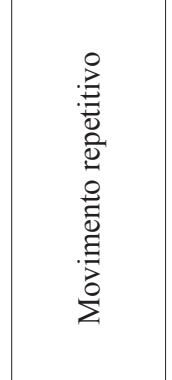 & 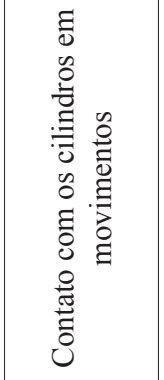 & 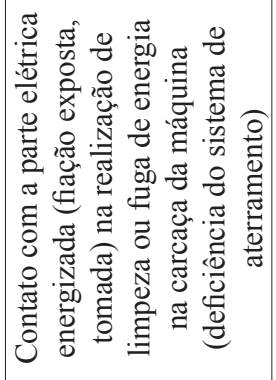 & 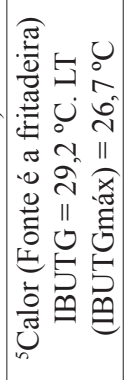 & 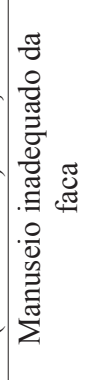 \\
\hline 芜 & \multicolumn{7}{|c|}{ 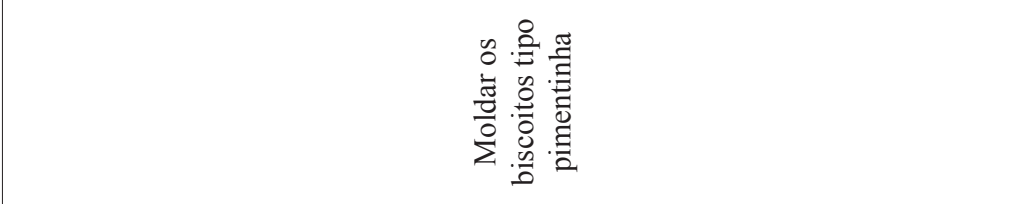 } \\
\hline
\end{tabular}




\begin{tabular}{|c|c|c|c|c|c|c|c|c|}
\hline 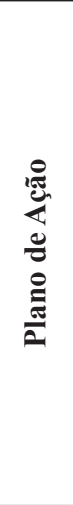 & 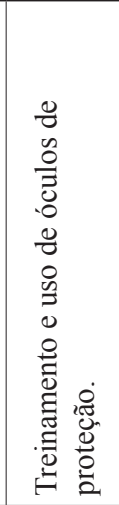 & 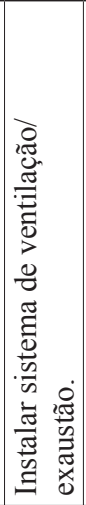 & 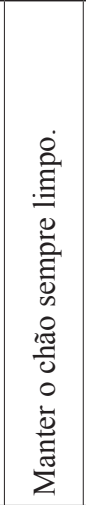 & 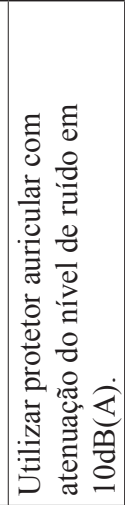 & 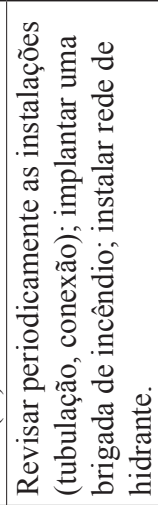 & 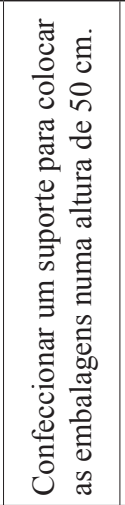 & 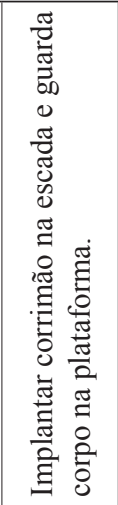 & 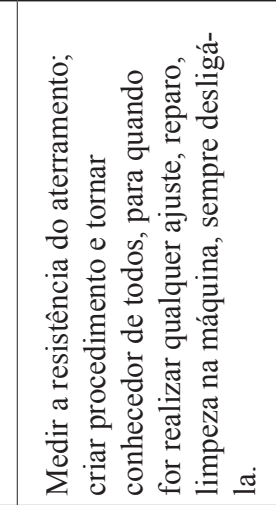 \\
\hline 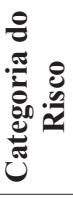 & $\overline{0}$ & 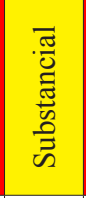 & $\begin{array}{l}\overline{0} \\
\frac{0}{0} \\
\frac{0}{0}\end{array}$ & $\stackrel{0}{\circ}$ & 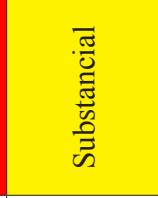 & o & & \\
\hline a & లె & $\infty$ & $\underset{\sim}{\infty}$ & $\stackrel{\infty}{\sim}$ & $\infty$ & 우 & to & 8 \\
\hline$\tilde{\omega}$ & $\nabla$ & $\infty$ & $\nabla$ & $\nabla$ & 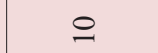 & in & $\infty$ & $a$ \\
\hline$\simeq$ & 0 & $\sim$ & 0 & 0 & $m$ & 0 & $\sim$ & $\sim$ \\
\hline$\Sigma$ & $m$ & $m$ & $m$ & $m$ & $m$ & $m$ & $m$ & $m$ \\
\hline 되 & - & $m$ & - & - & $\nabla$ & N & $m$ & $\nabla$ \\
\hline $\bar{n}$ & $\infty$ & 으 & $r$ & $r$ & $\infty$ & $\infty$ & $\infty$ & $r$ \\
\hline$\stackrel{a}{a}$ & - & $n$ & 0 & - & - & - & - & - \\
\hline త & $m$ & $m$ & $m$ & N & $m$ & $m$ & $m$ & $\sim$ \\
\hline 工 & $\nabla$ & $\nabla$ & $\nabla$ & $\nabla$ & $\nabla$ & $\nabla$ & $\nabla$ & $\nabla$ \\
\hline$\frac{\text { ral }}{\mathbf{z}}$ & z & z & z & z & z & z & z & z \\
\hline 离 & 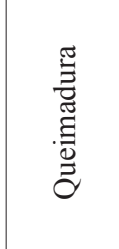 & 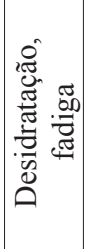 & 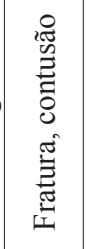 & 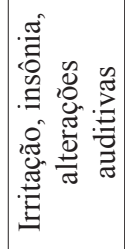 & 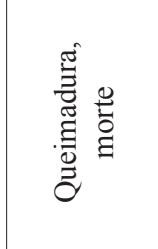 & 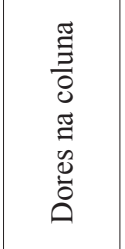 & 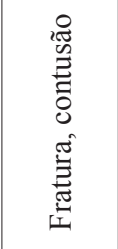 & 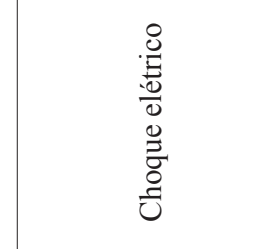 \\
\hline 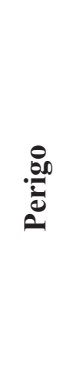 & 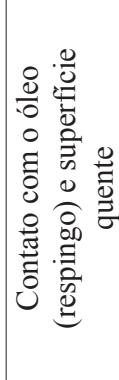 & 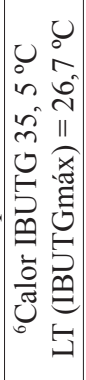 & 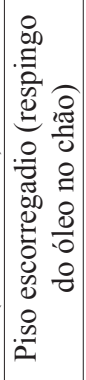 & 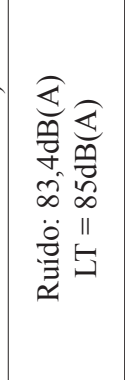 & 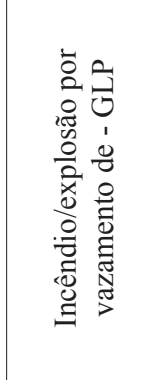 & 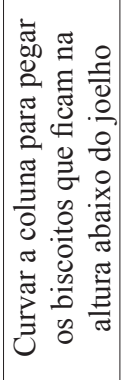 & 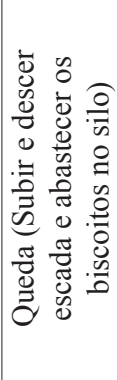 & 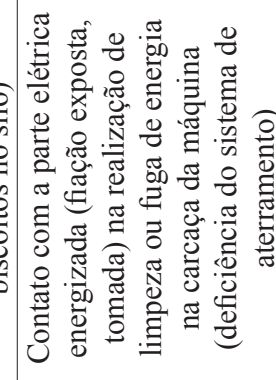 \\
\hline$\frac{0}{2}$ & \multicolumn{5}{|c|}{ 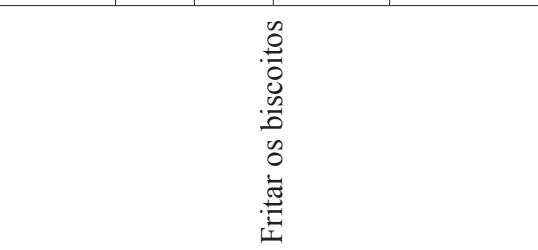 } & 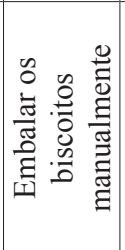 & \multicolumn{2}{|r|}{ 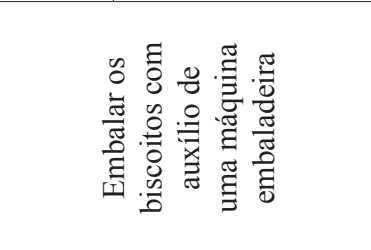 } \\
\hline
\end{tabular}




\begin{tabular}{|c|c|c|c|c|c|c|c|c|c|c|}
\hline 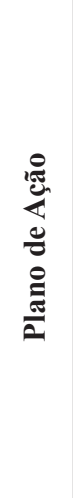 & 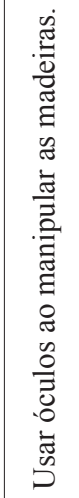 & 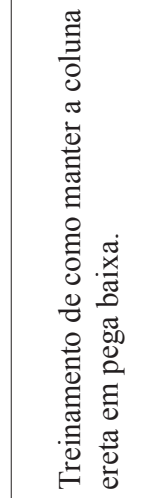 & 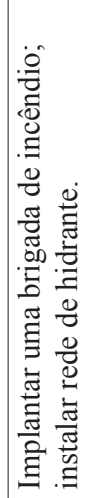 & 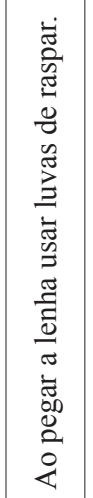 & 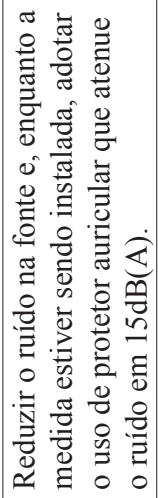 & 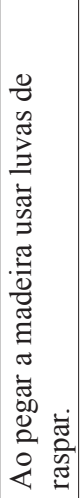 & 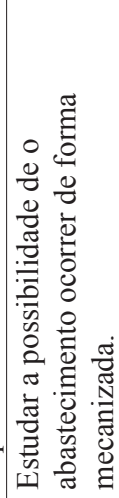 & 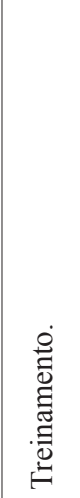 & 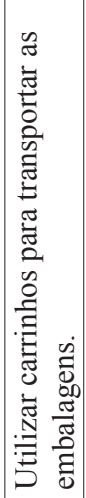 & 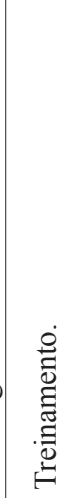 \\
\hline 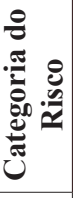 & & $\frac{\sum_{0}^{\frac{\pi}{4}}}{\frac{0}{0}}$ & 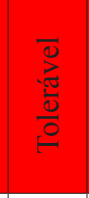 & 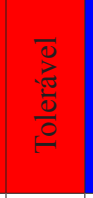 & & $\stackrel{ }{0}$ & 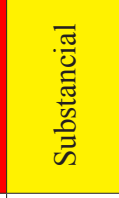 & 웅 & 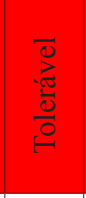 & $\begin{array}{l}\overline{0} \\
\stackrel{\bar{g}}{0} \\
\frac{0}{0} \\
\stackrel{0}{0}\end{array}$ \\
\hline a & $\tilde{m}$ & f & $\stackrel{\sim}{\sim}$ & f & $\widehat{6}$ & $\stackrel{\sim}{\sim}$ & 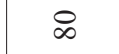 & $\tilde{m}$ & $\stackrel{\sim}{\sim}$ & $\stackrel{\infty}{\sim}$ \\
\hline$\tilde{n}$ & $\nabla$ & in & $\nabla$ & in & $r$ & $\nabla$ & in & in & $\nabla$ & $\nabla$ \\
\hline$\simeq$ & 0 & 0 & - & 0 & - & 0 & $\sim$ & 0 & 0 & 0 \\
\hline$\Sigma$ & $m$ & $m$ & 0 & $m$ & $m$ & $m$ & $n$ & $m$ & $n$ & $n$ \\
\hline$x$ & - & $\sim$ & $n$ & 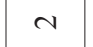 & $m$ & - & $m$ & $\sim$ & - & - \\
\hline $\bar{n}$ & $\infty$ & $\infty$ & $r$ & $\infty$ & $a$ & $r$ & 으 & $r$ & $r$ & $r$ \\
\hline 总 & - & - & 0 & - & $N$ & 0 & $m$ & 0 & - & - \\
\hline$\overleftrightarrow{u}$ & $m$ & $m$ & $n$ & $m$ & $m$ & $m$ & $m$ & $m$ & $N$ & $\sim$ \\
\hline II & $\nabla$ & $\nabla$ & $\nabla$ & $\nabla$ & ナ & $\nabla$ & $\nabla$ & $\nabla$ & $\nabla$ & $\nabla$ \\
\hline 됙 & z & z & z & Z & Z & Z & $z$ & z & Z & Z \\
\hline 薝 & 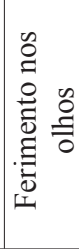 & 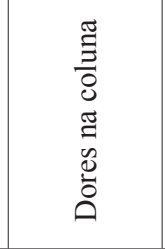 & 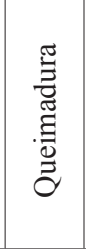 & 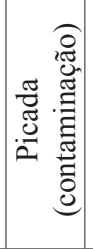 & 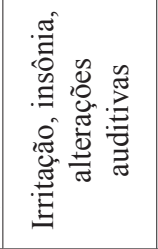 & نัّ & 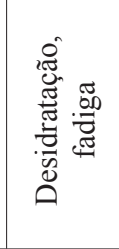 & 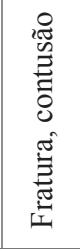 & 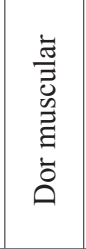 & 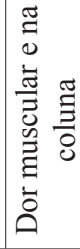 \\
\hline 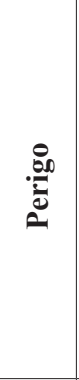 & 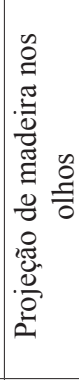 & 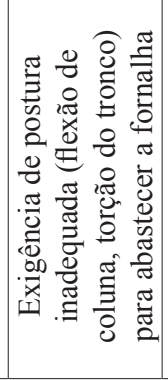 & 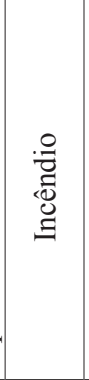 & 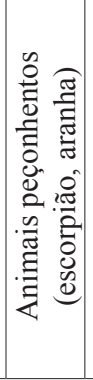 & 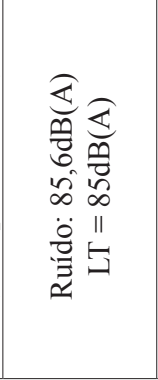 & 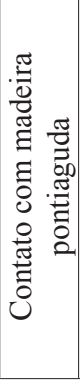 & 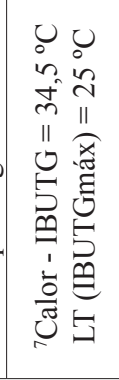 & 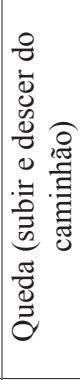 & 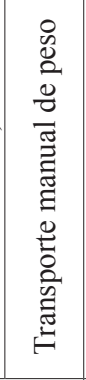 & 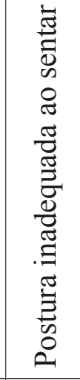 \\
\hline : & & & & 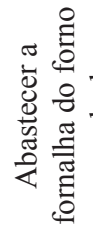 & & & & \multicolumn{2}{|c|}{ 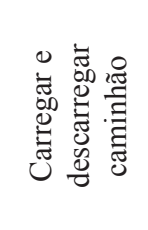 } & 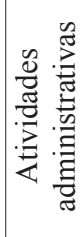 \\
\hline
\end{tabular}


pela disposição e característica dos fornos, pois dois deles são à lenha e estão instalados em ambiente fechado. As recomendações para redução do calor na empresa " $\mathrm{B}$ " passam primeiramente pela melhoria do sistema de ventilação e exaustão no ambiente em que estas atividades são desenvolvidas.

$\mathrm{Na}$ empresa "A", os níveis de iluminância em duas das 12 atividades do setor de produção foram classificados na categoria de risco trivial, enquanto que as demais atividades, foram classificadas na categoria de risco tolerável. Para estes casos, recomenda-se a execução de um projeto por profissionais habilitados para adequação dos níveis de iluminância de acordo com o estabelecido pela NR 17 (Brasil, 2007). Na empresa "B", a avaliação dos níveis de iluminância de todas as atividades, resultou na classificação da significância do risco na categoria trivial (Figura 5).

Em relação aos riscos químicos identificados nas empresas "A" e "B", o contato com a farinha de trigo foi o principal fator encontrado. No entanto, em função do tempo de exposição e da forma como é utilizada, o risco por inalação é baixo, sendo considerado como trivial, e, por contato, considerado como tolerável, necessitando de ações preventivas para evitar processos alérgicos, que, em casos de alta concentração, poderão causar asma. Para evitar o contato direto com a farinha, recomenda-se o uso de luvas tipo procedimento, acompanhado de treinamento para utilização correta, conservação e troca do Equipamento de Proteção Individual
(EPI) - luva, conforme recomendações do item 23 da NR18 (Brasil, 2012b).

As empresas " $\mathrm{A}$ " e "B" apresentam aspectos ergonômicos bastante similares em suas atividades, conforme a NR 17 (Brasil, 2007). Esses aspectos são caracterizados principalmente pela flexão da coluna vertebral e por movimentos repetitivos de mãos, punhos e braços, que são causadores de LER/DORT - Lesões por Esforço Repetitivo/Distúrbios Osteomusculares Relacionados ao Trabalho. Na empresa "B", foi detectado, na atividade moldar biscoito na pingadeira, que há um acentuado risco ergonômico por exigência de postura corporal inadequada, como: flexão do pescoço, rotação da coluna vertebral para esquerda, elevação da perna esquerda com movimentos repetitivos para acionar o pedal, localizado a $20 \mathrm{~cm}$ acima do piso. Para evitar flexão da coluna nas tarefas em que os trabalhadores têm de se abaixar para realizar parte da atividade, as empresas devem aumentar $50 \mathrm{~cm}$ da base da máquina amassadeira e confeccionar suportes com altura de $50 \mathrm{~cm}$ para colocar os biscoitos prontos, para a atividade de embalagem.

Nas atividades com movimentos repetitivos em ambas as empresas e na atividade de moldar biscoito na pingadeira na empresa " $B$ ", sugere-se que haja um rodízio de função, implantação de ginástica laboral com orientação de profissional habilitado três vezes por semana e descanso com intervalos de dez minutos a cada hora trabalhada, com a indicação de que os trabalhadores realizem, neste intervalo, alongamentos

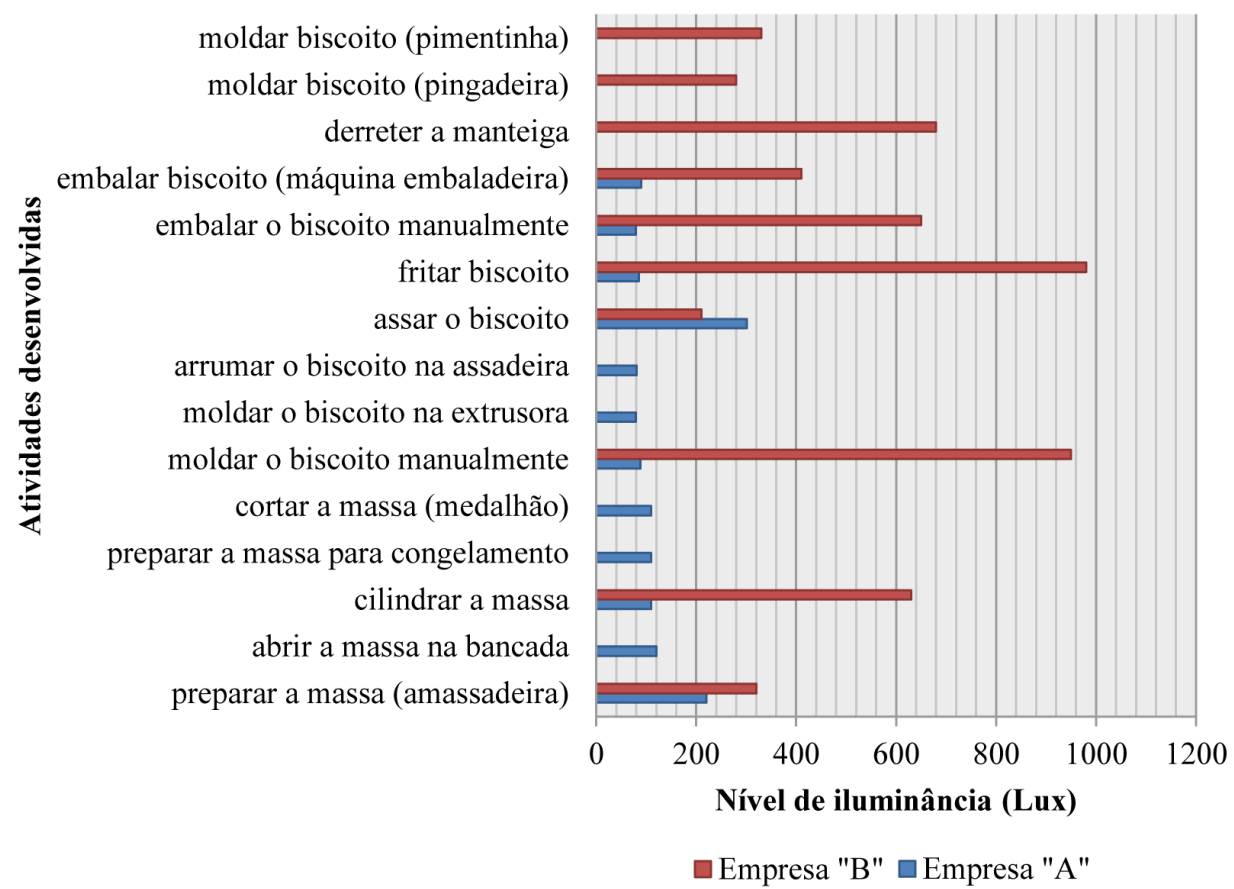

Figura 5. Nível de iluminância (Lux) nas empresas "A" e "B". Fonte: Dados da pesquisa. Os índices em 0 indicam ausência da atividade na empresa. 
adequados à função exercida, segundo a orientação e o aprendizado na ginástica laboral.

Foram identificados como principais riscos de acidentes a parte girante de máquina (cilindros, polias, correias) sem proteção (NR 12), contato com parte elétrica (NR 10) e incêndio/explosão por vazamento de GLP - gás liquefeito de petróleo (NR 16, NR 18, NR 20 e NR 23) e transporte manual de tacho contendo líquido superaquecido (óleo e manteiga) (NR 9). Tais riscos, segundo as NR associadas podem causar esmagamento e amputação, choque elétrico, queimaduras, problemas respiratórios e até óbito (Brasil, 1994, 2004, 2011b, 2011c, 2012b, c, d). De pequena proporção, foram identificados os riscos de queda e contato com superfícies quentes, como o forno, as assadeiras e o tacho, o contato com a faca e respingo de óleo quente, o que pode ocasionar pequenas lesões de pele.

Quanto aos riscos de acidente apontados anteriormente na máquina de cilindros das duas empresas, elas devem adequá-la às condições de segurança conforme o item 4 do Anexo 6 da NR 12 (Brasil, 2011b). Para a proteção de sistema de transmissão de motor (polias e correias), as empresas devem colocar proteção fixa, de modo que o trabalhador não tenha acesso às partes girantes. Na parte elétrica, as empresas devem adotar medidas de precauções, contratando profissional habilitado para projeto e manutenção das instalações, incluindo a verificação do sistema de aterramento. A empresa deve proibir profissional que não seja habilitado de realizar qualquer serviço envolvendo eletricidade. Além disso, deve determinar, por meio de procedimentos, que os trabalhadores, ao realizarem qualquer limpeza ou reparo nos seus equipamentos, o façam com os aparelhos desligados.

Com relação ao risco de incêndio/explosão por vazamento de GLP, recomenda-se que a empresa inspecione periodicamente as tubulações e equipamentos que compõem o sistema de distribuição do gás e promova a implantação, entre os trabalhadores, de uma brigada de combate a incêndio com capacitação técnica para desempenhar a função.

No transporte manual de tacho contendo líquido superaquecido, sugere-se o transporte por meio de um carrinho com bacia de contenção para apoio do tacho e evitar derramamentos, devendo o operador fazer uso de óculos de segurança de ampla visão.

No item que indica os riscos de queda, sugere-se, no caso da empresa "B", que seja instalado, na escada da máquina de embalar, um corrimão e guarda-corpo na sua plataforma; e, na empresa "A", que seja instalada uma escada com as mesmas orientações especificadas para a empresa "B". Já no caso do contato com a superfície quente, é indicado o uso de luvas de vaqueta e, no risco de corte com a faca, uso de luva de malha de aço.

\section{Considerações finais}

Neste trabalho, foi dado enfoque ao meio ambiente artificial, cultural e do trabalho, pois o objeto de estudo proposto, "o ambiente de trabalho na indústria de panificação", promove um olhar sobre esses três aspectos. Assim, diante dos parâmetros avaliados, é possível afirmar que as empresas estudadas apresentam significativas atividades responsáveis diretamente pela ocorrência de riscos ocupacionais nos ambientes da indústria de panificação.

A metodologia permitiu sintetizar, identificar, analisar e avaliar os riscos, para fomentar a elaboração mais adequada na organização e implantação de programas para gerenciamento de riscos, de forma a identificá-los e propor soluções corretivas ou preventivas.

Dos parâmetros de riscos avaliados, identificou-se que a empresa "B" foi a que apresentou maior exposição a riscos, com potencial de causar danos à saúde e à integridade física dos seus trabalhadores. Isto mostra que a prevenção de riscos em suas atividades deve ser realizada de imediato.

É importante ressaltar que os gastos gerados pela empresa com a prevenção de acidentes e doenças do trabalho devem ser vistos como um investimento que contribuirá para a melhoria das condições dos ambientes de trabalho, podendo ainda refletir positivamente em melhor desempenho das atividades por parte dos trabalhadores. Além disso, deve-se considerar que, com a eliminação ou minimização das situações de risco, a empresa evitará gastos com adicional de insalubridade, indenizações e multas trabalhistas.

Outro aspecto importante é que, com a implantação do Sistema de Gestão em Saúde e Segurança do Trabalhador (SGSST), a empresa promoverá um meio ambiente, tanto no aspecto físico quanto no das relações humanas, que favorecerá melhor qualidade de vida a seus trabalhadores. Ressalta-se que o atendimento à regulamentação é uma das etapas deste processo, devendo as empresas, a ampliação das suas ações, visando assim a promoção de um meio ambiente mais salutar.

Por fim, a ferramenta aplicada neste trabalho, além de auxiliar na implantação de um SGSST, poderá ser utilizada na implantação de um Sistema de Gestão Ambiental, baseado ou não na série ISO 14000, servindo assim de auxílio a futuros estudos e ações nas empresas.

\section{Referências}

Associação Brasileira de Normas Técnicas - ABNT. (1992). NBR 5413: iluminância de interiores. Rio de Janeiro.

Associação Brasileira de Normas Técnicas - ABNT. (1997). NBR 14009: segurança de máquinas: princípios para apreciação de riscos. Rio de Janeiro.

Associação Brasileira de Normas Técnicas - ABNT. (1998). NBR 14153: segurança de máquinas: partes de sistemas 
de comando relacionados à segurança: princípios gerais para projeto. Rio de Janeiro.

Associação Brasileira de Normas Técnicas - ABNT. (2004). ABNT NBR ISO 14001: sistemas da gestão ambiental: requisitos com orientações para uso. Rio de Janeiro.

Australian Standard/New Zealand Standard - AS/NZS. (2004). AS/NZS 4360: risk management. Australia: Standards Australia International Ltd. \& Standards New Zealand.

Brasil. Ministério do Trabalho e Emprego. (1994). Norma Regulamentadora 9: Programa de Prevenção de Riscos Ambientais. Publicação Portaria GMn.$^{\circ} 3.214$, de 08 de junho de 1978. Alterações/Atualizações Portaria SSST n. ${ }^{\circ} 25$, de 29 de dezembro de 1994. Brasília, DF: Diário Oficial da União.

Brasil. Conselho Nacional de Saúde - CNS. (1996). Resolução 196: diretrizes e normas regulamentadoras de pesquisas envolvendo seres humanos no Brasil. Brasília, DF: Diário Oficial da União.

Brasil. Ministério do Trabalho e Emprego. (2004). Norma Regulamentadora 10: Segurança em instalações e serviços em eletricidade. Publicação Portaria GMn. ${ }^{\circ}$ 3.214, de 08 de junho de 1978. Alterações/Atualizações Portaria GM n. ${ }^{\circ}$ 598, de 07 de dezembro de 2004. Brasília, DF: Diário Oficial da União.

Brasil. Ministério do Trabalho e Emprego. (2007). Norma Regulamentadora 17 : Ergonomia. Publicação Portaria GM n. ${ }^{\circ} 3.214$, de 08 de junho de 1978. Alterações/ Atualizações Portaria SIT n. ${ }^{\circ} 13$, de 21 de junho de 2007. Brasília, DF: Diário Oficial da União.

Brasil. Ministério do Trabalho e Emprego. (2010). Classificação Brasileira de Ocupações: $C B O$ (3. ed., Vol. 2). Brasília. 592 p.

Brasil. Ministério do Trabalho e Emprego. (2011a). Norma Regulamentadora 15 -Atividades e operações insalubres. Publicação Portaria GMn n. 3.214 , de 08 de junho de 1978. Alterações/Atualizações Portaria SIT n. ${ }^{\circ} 291$, de 08 de dezembro de 2011. Brasília, DF: Diário Oficial da União.

Brasil. Ministério do Trabalho e Emprego. (2011b). Norma Regulamentadora 12: segurança no trabalho em maquinas e equipamentos. Publicação Portaria GM n. ${ }^{\circ}$ 3.214, de 08 de junho de 1978. Alterações/ Atualizações Portaria SIT n. ${ }^{\circ} 293$, de 08 de dezembro de 2011. Brasília, DF: Diário Oficial da União.

Brasil. Ministério do Trabalho e Emprego. (2011c). Norma Regulamentadora 23: proteção contra incêndios. Publicação Portaria GMn ${ }^{\circ} 3.214$, de 08 de junho de 1978. Alterações/Atualizações Portaria SIT n. ${ }^{\circ} 221$, de 06 de maio de 2011. Brasília, DF: Diário Oficial da União.

Brasil. Ministério da Previdência Social. (2012a). Anuário estatístico da previdência social. Brasília. Recuperado em maio de 2014, de http://www.previdencia.gov.br/ estatisticas

Brasil. Ministério do Trabalho e Emprego. (2012b). Norma Regulamentadora 18: condições e meio ambiente de trabalho na indústria da construção. Publicação Portaria GM n. ${ }^{\circ}$ 3.214, de 08 de junho de 1978. Alterações/ Atualizações Portaria SIT n. ${ }^{\circ} 318$, de 08 de maio de 2012. Brasília, DF: Diário Oficial da União.

Brasil. Ministério do Trabalho e Emprego. (2012c). Norma Regulamentadora 16: atividades de operações perigosas. Publicação Portaria GM n ${ }^{\circ} 3.214$, de 08 de junho de 1978. Alterações/Atualizações Portaria SIT n. ${ }^{\circ}$ 312, de 23 de março de 2012. Brasília, DF: Diário Oficial da União.

Brasil. Ministério do Trabalho e Emprego. (2012d). Norma Regulamentadora 20: líquidos, combustiveis e inflamáveis. Publicação Portaria GMn n ${ }^{\circ} 3.214$, de 08 de junho de 1978. Alterações/Atualizações Portaria SIT $n .^{\circ}$ 308, de 29 de fevereiro de 2012. Brasília, DF: Diário Oficial da União.

British Standards Institution - BSI. (2004). BS 8800: occupational health and safety management systems: guide. London.

Denipotti, M. E. P., \& Robazzi, M. L. C. C. (2011). Riscos ocupacionais identificados nos ambientes de panificação brasileiros. Ciencia y Enfermería, 17(1), 117-127. http://dx.doi.org/10.4067/S0717-95532011000100012.

Fundação Jorge Duprat Figueiredo de Segurança e Medicina do Trabalho - Fundacentro. (2002). NHO 06: Norma de higiene ocupacional: procedimento técnico: avaliação da exposição ocupacional ao calor. Brasília.

Maia, L. R., \& Rodrigues, L. B. (2012). Saúde e segurança no ambiente rural: uma análise das condições de trabalho em um setor de ordenha. Ciência Rural, 42(6), 1134-1139. http://dx.doi.org/10.1590/S010384782012000600030 .

Melo A. S. J., \& Rodrigues, C. L. P. R. (2005). O risco de acidente de trabalho na indústria de panificação: o caso das máquinas de cilindro de massa. In XX Encontro Nacional de Engenharia de Produção. Porto Alegre.

Occupational Health and Safety Series - OHSAS. (2007). OHSAS 18001: sistema de gestão de saúde e segurança ocupacional. London.

Rego, M. A. M., \& Lima, G. B. A. (2006). Metodologia qualitativa de avaliação de riscos operacionais de segurança, meio ambiente e saúde ocupacional: uma contribuição ao gerenciamento de riscos das organizações. In III Simpósio de Excelência em Gestão e Tecnologia. Rio de Janeiro: AEDB.

Rocha, F. B. A., Oliveira, L. F. A., Campos, M. C., \& Carvalho, R. J. M. (2011). Riscos do trabalho na indústria de panificação: estudo de caso em uma panificadora de Natal, RN. In XXXI Encontro Nacional de Engenharia de Produção. Belo Horizonte, MG. 
Rodrigues, L. B., Santana, N. B., \& Rodrigues, M. S. B. (2012). Identificação dos Riscos Ocupacionais em uma Unidade de Produção de Derivados de Carne. UNOPAR Cientifica: Ciências Biológicas e da Saúde, $14,115-119$.

Rodrigues, L. B., Santana, N. B., Bonomo, R. C. F., \& Silva, L. B. (2008). Apreciação ergonômica do processo de produção de queijos em indústrias de laticínios. Revista Produção Online, 8(1), 1-18.

Sasaki, L. H. (2007). Educação para segurança do trabalho. São Paulo: Corpus.

Serviço Social da Indústria - SESI. (2005). Manual de segurança e saúde no trabalho: indústria da panificação. São Paulo. 